\title{
Hydrodynamic cavitation in microsystems. I. Experiments with deionized water and nanofluids
}

\author{
M. Medrano, P. J. Zermatten, C. Pellone, J. P. Franc, and F. Ayela ${ }^{\text {a) }}$ \\ Laboratoire des Ecoulements Géophysiques et Industriels, UJF Grenoble 1 - CNRS, BP 53, \\ 38041 Grenoble Cedex 9, France
}

\begin{abstract}
An experimental study of hydrodynamic cavitation downstream microdiaphragms and microventuris is presented. Deionized water and nanofluids have been characterized within silicon-Pyrex micromachined devices with hydraulic diameters ranging from $51 \mu \mathrm{m}$ t $010404 \mu \mathrm{m}$. The input pressure could reach up to 10 bars, and the flow rate was below 1 liter per hour. The output pressure of the devices was fixed at values ranging from 0.3 bar to 2 bars, so that it was possible to study the evolution of the cavitation number as a function of the Reynolds number in the orifice of the diaphragms or in the throat of the venturis. A delay on the onset of cavitation has been recorded for all the devices when they are fed with deionized water, because of the metastability of the liquid and because of the lack of roughness of the walls. For the first time, hydrodynamic cavitation of nanofluids (nanoparticles dispersed into the liquid) has been considered. The presence of nano-aggregates in the liquid does not exhibit any noticeable effect on the cavitation threshold through the venturis. However, such a presence has a strong influence on the cavitation onset in microdiaphragms: above a critical volume solid concentration of $\approx 10^{-5}$, the metastability is broken and the nanofluids behave as tap water filled up with large nuclei. These microdevices, where a low amount of fluid is required to reach cavitating flows, appear to be useful tools in order to study cavitating phenomena in localized area with specific fluids.
\end{abstract}

\section{INTRODUCTION}

Hydrodynamic cavitation is generally defined as the phenomenon of nucleation, growth, and collapse of vapor bubble, in a region where the static pressure of a liquid falls below its vapour pressure. Simple geometries, such as orifices or venturi, may generate large pressure drops within a moving liquid. As indicated by Bernoulli equation, the low pressure regions are generated by the flowing liquid via velocity changes. A low pressure is expected in the regions of high velocity as the throat of a venturi or through an orifice. Cavitation can also develop in a turbulent shear layer due to the formation of local cores of fluid vortices in submerged jets. ${ }^{1}$ During the growth phase of the bubble, liquid from the surrounding medium evaporates into the cavity. When the bubble is subjected to a higher pressure (because it has moved towards a higher pressure zone), it is collapsing down via a rather violent mechanism.

Hydrodynamic cavitation has been largely studied, due to the negative consequences caused by the collapse of the vapor bubbles once the flow recovers a static pressure above the vapor pressure. More recently, possible favorable consequences of hydrodynamic cavitation have been investigated. Chemistry induced by hydrodynamic cavitation has been compared to that induced by acoustic cavitation. ${ }^{2-5}$ Radicals produced from hydrodynamic cavitation are expected to enhance the treatment of wastewaters and other pollutants. ${ }^{6}$ The synthesis of nanomaterials by high shear hydrodynamic

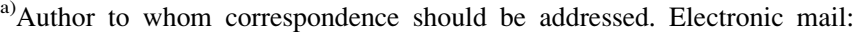
frederic.ayela@hmg.inpg.fr.
}

cavitation has also been investigated. ${ }^{7,8}$ The high expected temperatures inside collapsing bubbles and the efficiency of the mixing of chemical species are assumed to enhance the synthesis of solid materials. Each cavitation bubble appears as a micro-reactor, whose efficiency depends on the maximum temperature reached in its core.

Heterogeneous bubble nucleation is enhanced when a solid phase is dispersed in the liquid. The influence of solid microparticles in water on the tensile strength of water has already been studied ${ }^{9,10}$ but without taking into account the influence of the solid volume concentration. Microparticles are likely to enhance cavitation inception because of trapped gas on their corrugated surfaces. Nanoparticles should be of no effect on the onset of cavitation, because of enhanced tension effects related to their very small radius of curvature. The effect of nanoparticles on the liquid-gas surface tension of nanofluids ${ }^{11}$ and on the dynamics of gas bubbles ${ }^{12}$ has been recently reported. An anomalous gas hold up in a bubble column with nanofluids has also been noticed. ${ }^{13}$ To our knowledge, no hydrodynamic cavitation experiments with nanofluids have been reported up to now.

Some authors use the term of cavitation to describe any bubble nucleation and collapse phenomenon, caused either by a heat pulse ${ }^{14}$ or by a laser pulse. ${ }^{15-17}$ They are mainly motivated by the study of bubble dynamics and use microfluidic systems for their experimental or analytical investigations. Hydrodynamic cavitation through microchannels has been studied only very recently. ${ }^{18-20}$ At the time, these papers were written, there were still some discrepancies in the literature about the validity of the laws of hydrodynamics at microscales. So, there was a need to investigate similarities and 
differences between cavitation at microscale and conventional cavitation. Today, the controversy about unusual physical effects in microflows is over. ${ }^{21,22}$ Microchannels should now be considered as "labs on chip" allowing experiments with a relative low amount of fluid. On the one hand, that could be efficient tools for any studies about the physico-chemical applications of hydrodynamic cavitation cited above. On the other hand, microchannels with diaphragms or venturi may act as facilities devoted to test microgeometries as encountered in diesel engines nozzles. Otherwise, from a more fundamental point of view, mastering hydrodynamic cavitation in a microchannel should make possible fine observations of the bubble dynamics, as already performed but from laser induced bubbles $^{16,17}$ or from acoustically driven waves. ${ }^{23}$

Even if the classical laws of hydrodynamics are valid at microscale, micromachined devices exhibit some special peculiarities not attainable in larger ducts. It is well-known that the onset of cavitation is related to the tensile strength of the liquid, rather than the vapor pressure. The tensile strength of the liquid depends on free stream nuclei, and on surface nuclei present in the surfaces bounding the flow. With microfluidic devices, surface effects become predominant. Moreover, microfabrication gives way to very smooth surfaces. And as the residence time of any nuclei in a low pressure area is reduced because of the smallest sizes of the restricted area, a delay in the inception of cavitation is expected with micro-diaphragms and micro venturi.

The present investigation is an experimental study of hydrodynamic cavitation performed on various microfluidic geometries. Micro-orifices with different hydraulic diameters $\mathrm{d}_{\mathrm{H}}$ as well as micro venturi with different throats and different diffusers angles have been tested. Venturi tubes at macroscale are used as cavitation susceptibility meters ${ }^{24}$ and the extension of this process at microscale should be considered. The working fluids were de-ionized water and nanofluids. The influence of the solid volume concentration of nanoparticles inseminated into the water has been studied. That was in order to scrutinize the role of homogeneous and heterogeneous nucleation. Other parameters such as the Reynolds number in the orifices and the exit pressure of the flow have been considered. Our analytical approach and our results confirm some of previous results obtained with similar geometries, ${ }^{18-20}$ but also give a finest appreciation on the transition towards cavitation at the microscale. High-speed camera recordings of the flow have been performed and will be presented and analyzed in a companion paper.

Section II recalls the analytical expressions related to hydrodynamic cavitation in diaphragms and venturis and underlines the specific trends involved by a reduction of size. Section III describes the micromachining of the devices and the experimental set up. Results and discussion are provided in Sec. IV, and Sec. V presents the conclusions.

\section{FORMULATION}

\section{A. Micro diaphragms}

The design of the microdiaphragms is shown in Fig. 1. Large tanks, where the velocity of the fluid is negligible, are located at the ends of the channels, with static pressures noted $\mathrm{P}_{\text {in }}$ and $\mathrm{P}_{\text {out }}$, respectively. The fluid flows through a rectangular microchannel of width $\mathrm{W}=510 \mu \mathrm{m}$, length $\mathrm{L}=1500 \mu \mathrm{m}$, and height $\mathrm{H}$ and is submitted to a regular pressure drop between $1^{\prime}$ and 1 , as between 3 and $3^{\prime}$. The presence of a diaphragm of width $\mathrm{w} \ll \mathrm{W}$, length $\mathrm{l}=100 \mu \mathrm{m}$ and same height as the channel, increases the velocity of the fluid, that reaches a maximum at the vena contracta (point 2).

The area of the cross section of the flow, noted $A_{2}$, is smaller than the area of the diaphragm $\left(\mathrm{A}_{0}\right)$, and the contraction coefficient $\mathrm{C}_{\mathrm{c}}$ is defined by $\mathrm{C}_{\mathrm{c}}=\mathrm{A}_{2} / \mathrm{A}_{0}$. From point 3 to $3^{\prime}$, the fluid flows through a channel of same shape as between $1^{\prime}$ and 1 . The calculation of the regular pressure drop along the channel and of the singular pressure drop through the orifice leads to

$$
P_{\text {in }}-P_{\text {out }}=\frac{24 \eta L}{W H^{3}}\left(1+\frac{H}{W}\right)^{2} Q+\frac{\rho}{2 C_{d}^{2}} \frac{1}{w^{2} H^{2}} Q^{2}
$$

where $\mathrm{Q}$ is the flow rate, $\eta$ is the viscosity of the fluid, $\rho$ is its density, respectively, and $\mathrm{C}_{\mathrm{d}}$ is the discharge coefficient of the orifice. By noting $\mathrm{u}_{\mathrm{i}}$ the average velocity of the fluid at point $\mathrm{i}$, and by applying Bernoulli equation, one finds

$$
\begin{gathered}
P_{1}+\frac{1}{2} \rho u_{1}^{2}=P_{2}+\frac{1}{2} \rho u_{2}^{2}, \\
P_{3}+\frac{1}{2} \rho u_{1}^{2}=P_{2}+\frac{1}{2} \rho u_{2}^{2}-\Delta P_{1 \rightarrow 3},
\end{gathered}
$$

where $\Delta \mathrm{P}_{1 \rightarrow 3}=1 / 2 \rho\left(\mathrm{u}_{2}-\mathrm{u}_{1}\right)^{2} \quad$ with $\quad \mathrm{u}_{1}=\mathrm{Q} /(\mathrm{WH}) \quad$ and $\mathrm{u}_{2}=\mathrm{Q} /\left(\mathrm{C}_{\mathrm{c}} \mathrm{wH}\right)$.

There is not much loss between 1 and 2. Losses occur in the flow expansion from 2 to 3 and are due to the abrupt enlargement. They are given by the Borda-Carnot approach. We get

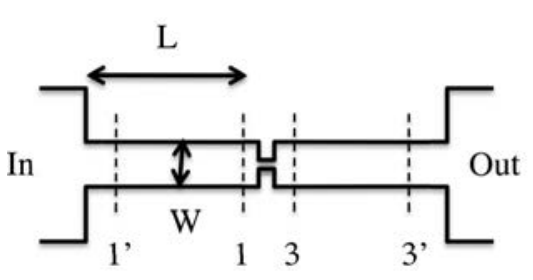

a)

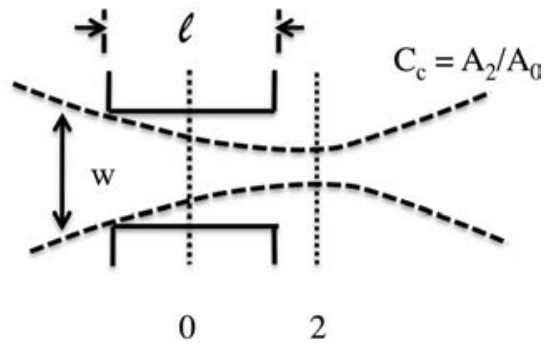

b)
FIG. 1. (a) General scheme of a rectangular channel with a micro-orifice inside. (b) zoom on the micro-orifice of width $w$ and (dashed) lines of the flow. At the vena contracta (2), the effective cross section of the jet is characterized by the contraction coefficient $\mathrm{C}_{\mathrm{c}}$. All the micro-diaphragms under test obeyed $\mathrm{W}=510 \mu \mathrm{m}, \mathrm{L}=1.5 \mathrm{~mm}$, and $\mathrm{l}=100 \mu \mathrm{m}$. Different heights $\mathrm{H}$ and width w were tested; their values are provided in Table I. 


$$
P_{2}=P_{\text {out }}+\frac{12 \eta L}{W H^{3}}\left(1+\frac{H}{W}\right)^{2} Q-\frac{\rho}{W^{2} H^{2}}\left(\frac{W}{w C_{c}}-1\right) Q^{2} .
$$

Equation (4) is a relationship between the static pressure at point 2 where it is expected to reach the minimum value of static pressure, and the flow rate. By increasing the flow rate from zero when $\mathrm{P}_{\text {out }}$ is fixed, there is first an increase of $\mathrm{P}_{2}$ due to regular pressure drops. The static pressure $\mathrm{P}_{2}$ reaches a maximum at a critical flow rate above which the quadratic term of Eq. (4) becomes predominant, and the pressure falls down. The smaller the critical flow is, the easier the condition $\mathrm{P}_{2}<\mathrm{P}_{\text {vap }}$ is reached (where $\mathrm{P}_{\text {vap }}$ is the vapour pressure). It can be easily shown that $\mathrm{H}>\mathrm{w}$ is a condition enhancing the access to low pressure values at point 2 , and it will be taken into account for the design of the devices. The condition $\mathrm{P}_{2}<\mathrm{P}_{\text {vap }}$ does not mean that cavitation should occur. As mentioned in the Introduction, the onset of cavitation is related to the tensile strength of the liquid rather than $P_{\text {vap. }}$. However, the knowledge of the flowrate $\mathrm{Q}=\mathrm{Q}_{\text {cav }}$ corresponding to $\mathrm{P}_{2}=\mathrm{P}_{\text {vap }}$ is an useful reference to analyse the experimental threshold of cavitation.

The condition $\mathrm{P}_{2}=\mathrm{P}_{\text {vap }}$ is reached when $\mathrm{Q}=\mathrm{Q}_{\text {cav }}$ with

$$
Q_{c a v}=W H\left[\frac{1}{\rho} \frac{P_{\text {out }}-P_{v a p}}{\frac{W}{w C_{c}}-1}\right]^{1 / 2}
$$

Equation (5) holds as long as $\mathrm{P}_{\text {out }} \gg 36 \mathrm{C}_{\mathrm{c}} \eta^{2} \mathrm{~L}^{2} \mathrm{w} /\left(\rho \mathrm{WH}^{4}\right)$; all of our experiments obeyed that last condition, that means that the linear term in Eq. (1) is negligible in front of the quadratic one. By increasing the pressure drop in the single liquid phase, cavitation should be expected to occur once $\mathrm{Q}>\mathrm{Q}_{\text {cav }}$ (i.e., $\mathrm{P}_{2}<\mathrm{P}_{\text {vap }}$ ). Once cavitation flows take place downstream the diaphragm, a decrease of the contraction coefficient is likely to occur when a liquid jet is surrounded by vapour clouds. As a consequence, by decreasing the pressure drop, cavitation should be expected to disappear when $\mathrm{Q}<\mathrm{Q}_{\text {cav }}^{\prime}$ (i.e., $\mathrm{P}_{2}>\mathrm{P}_{\text {vap }}$ ) where $\mathrm{Q}_{\text {cav }}^{\prime}$ is the new value of the flow rate corresponding to the new $\mathrm{C}_{\mathrm{c}}$ value in the two-phase flow regime. $\mathrm{Q}_{\text {cav }}^{\prime}$ should be slightly below $\mathrm{Q}_{\mathrm{cav}}$.

A relationship between the discharge coefficient $C_{d}$ and the contraction coefficient $\mathrm{C}_{\mathrm{c}}$ can be stated from

$$
P_{1}-P_{3}=\frac{\rho}{2 C_{d}^{2}} \frac{Q^{2}}{w^{2} H^{2}}=\frac{1}{2} \rho\left(u_{2}-u_{1}\right)^{2},
$$

leading to

$$
\frac{1}{C_{d}}=\frac{1}{C_{c}}-\frac{w}{W} .
$$

$C_{d}=0.6$ on a large range of Reynolds number, as long as the length 1 of the orifice is small compared to the hydraulic diameter. That last condition is not necessarily satisfied at microscale, and the values of $\mathrm{C}_{\mathrm{d}}$ may be rather different, as will be verified in Sec. IV A $1 .{ }^{25}$

The length $\mathrm{L}=1.5 \mathrm{~mm}$ upstream, the diaphragm was not always sufficiently long to give way to a laminar fully developed flow. We believe it was of minor importance because: (a) the regular pressure drop term in Eq. (1) is negligible. (b) The presence of the forward facing step due to the diaphragm has a major effect, since it creates a vortex area before the contraction.

We define the cavitation number $\sigma$ by

$$
\sigma=\frac{P_{3}-P_{v a p}}{1 / 2 \rho u_{0}^{2}} \approx \frac{2 w^{2} H^{2} P_{o u t}}{\rho Q^{2}} .
$$

Around the $\mathrm{Q}_{\mathrm{cav}}$ values, when $\mathrm{P}_{2}=\mathrm{P}_{\mathrm{vap}}$, Eq. (3) leads to

$$
\sigma=\sigma_{c a v}=\frac{2 w}{C_{d} W} .
$$

This critical value of the cavitation number depends on the dimensions of the orifice and on the discharge coefficient. The dimensionless cavitation numbers are related to the minimum static pressure values. These numbers will be plotted as a function of the Reynolds number, for different devices or for different operating conditions.

A specific peculiarity of microdiaphragms resides in the fact that the $\mathrm{Q}_{\mathrm{cav}}$ value can be reached in laminar flow, i.e., when the Reynolds number in the diaphragm $\operatorname{Re}_{\mathrm{d}}$ is still below the critical value 2300 which characterizes transition to turbulence.

The experimental relationships between $\mathrm{P}_{\text {in }}-\mathrm{P}_{\text {out }}$ and $\mathrm{Q}$ will be compared with Eq. (1). From the knowledge of the geometrical shape of the channels, it is easy to find the experimental values for $C_{d}$ which can be compared with the theoretical values. Then, it becomes possible to estimate the $\mathrm{Q}_{\text {cav }}$ values, and the corresponding $\sigma_{\text {cav }}$ number, and to compare these values with the experimental onset of cavitation.

\section{B. Micro venturi}

Similar calculations can be performed for micro venturi of height $\mathrm{H}$ as designed in the Figure 2. The pressure drop $\mathrm{P}_{\text {in }}-\mathrm{P}_{\text {out }}$ is the sum of the singular loss in the throttle and of the regular pressure drop between $\mathrm{O}$ and $\mathrm{L}$.

$$
\begin{aligned}
P_{\text {in }}-P_{\text {out }}= & \frac{1}{2} \rho\left[1-\left(\frac{w_{0}}{w_{E}}\right)^{2}\right]\left[\frac{1}{C_{v}^{2}}-1\right] u_{0}^{2} \\
& +2 u_{0} F\left(w_{0}, w_{L}, H\right)
\end{aligned}
$$

with

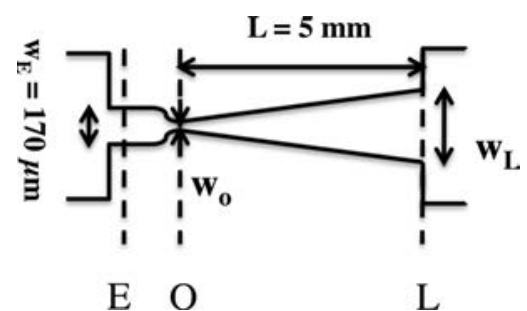

FIG. 2. General scheme of a micro venturi and notation was used in the text. $\mathrm{w}_{\mathrm{E}}$ and $\mathrm{L}$ were kept constant whatever were the other parameters of the devices. The set of $\mathrm{w}_{\mathrm{o}}$ and $\mathrm{w}_{\mathrm{L}}$ values tested is detailed in the text. 
$F\left(w_{0}, w_{L}, H\right)=3 \eta L\left[\frac{w_{L}+w_{0}}{w_{0} w_{L}^{2}}+\frac{4}{H w_{L}}+\frac{2 w_{0}}{H^{2}\left(w_{L}-w_{0}\right)} \ln \frac{w_{L}}{w_{0}}\right]$.

The $\mathrm{F}\left(\mathrm{w}_{\mathrm{o}}, \mathrm{w}_{\mathrm{L}}\right.$, and $\left.\mathrm{H}\right)$ function is related to the regular losses through the diffuser and has been calculated by assuming that there is no laminar separation between $\mathrm{O}$ and $\mathrm{L}$.

Equation (10) results from

$$
\begin{gathered}
P_{E}-P_{O}=\frac{1}{2 C_{v}^{2}} \rho\left[1-\left(\frac{w_{O}}{w_{E}}\right)^{2}\right] u_{0}^{2}, \\
P_{i n}=P_{E}+\frac{1}{2} \rho\left(\frac{w_{O}}{w_{E}}\right)^{2} u_{O}^{2},
\end{gathered}
$$

and

$$
P_{\text {out }}=P_{L}+\frac{1}{2} \rho u_{L}^{2}=P_{O}+\frac{1}{2} \rho u_{0}^{2}-2 u_{0} F\left(w_{0}, w_{L}, H\right),
$$

which allows us to write

$$
\begin{aligned}
P_{O} & =P_{\text {out }}+2 u_{0} F\left(w_{0}, w_{L}, H\right)-\frac{1}{2} \rho u_{O}^{2} \\
& =P_{\text {in }}-\frac{1}{2} \rho u_{0}^{2}\left[\frac{1}{C_{v}^{2}}-\left(\frac{1}{C_{v}^{2}}-1\right)\left(\frac{w_{O}}{w_{E}}\right)^{2}\right] .
\end{aligned}
$$

$\mathrm{P}_{\text {out }}$ is assumed to be a fixed pressure value. The venturi coefficient is noted $\mathrm{C}_{\mathrm{v}}$. It is Reynolds dependent and typical values $\mathrm{C}_{\mathrm{v}} \approx 0.6$ have been published at $\mathrm{Re} \approx 1000$, for micro venturis devices. $^{20}$

From Eq. (15), it becomes possible to find the critical velocity of the fluid in the throttle, above which the pressure $\mathrm{P}_{\mathrm{o}}$ falls below $\mathrm{P}_{\mathrm{vap}}$, and the corresponding pressure gradient. Once again, we are considering $\mathrm{P}_{\text {out }}$ as a fixed pressure value. One finds

$$
\begin{aligned}
Q_{\text {cav }}= & \frac{2 w_{0} H}{\rho} \\
& \times\left(F\left(w_{0}, w_{L}, H\right)+\sqrt{F^{2}\left(w_{0}, w_{L}, H\right)+\frac{\rho}{2}\left(P_{\text {out }}-P_{\text {vap }}\right)}\right) .
\end{aligned}
$$

In a same way as for the micro diaphragms, it can be shown that the $\mathrm{Q}_{\mathrm{cav}}$ value is easily reached when $\mathrm{H}>\mathrm{w}_{0}$.

The cavitation number is now defined by

$$
\sigma=\frac{P_{L}-P_{v a p}}{1 / 2 \rho u_{0}^{2}} \approx \frac{2\left(P_{\text {out }}-P_{\text {vap }}\right)}{\rho} \frac{H^{2} w_{O}^{2}}{Q^{2}},
$$

and when $\mathrm{P}_{\mathrm{O}}=\mathrm{P}_{\mathrm{vap}}$

$$
\begin{aligned}
\frac{1}{\sigma_{\text {cav }}}=1 & +\frac{4 F\left(w_{0}, w_{L}, H\right)}{\rho\left(P_{\text {out }}-P_{\text {vap }}\right)} \\
& \times\left[F\left(w_{0}, w_{L}, H\right)+\sqrt{F^{2}\left(w_{0}, w_{L}, H\right)+\frac{\rho}{2}\left(P_{\text {out }}-P_{\text {vap }}\right)}\right] .
\end{aligned}
$$

The critical cavitation number $\sigma_{\text {cav }}$ is now dependent on the exit pressure.
The relative contribution of $\mathrm{F}\left(\mathrm{w}_{\mathrm{o}}, \mathrm{w}_{\mathrm{L}}\right.$, and $\left.\mathrm{H}\right)$ in Eq. (10) is not negligible in front of the quadratic evolution of the pressure drop. So, the experimental evolution $\Delta \mathrm{P}=\mathrm{P}_{\text {in }}-$ $\mathrm{P}_{\text {out }}$ plotted as a function of the flow rate $\mathrm{Q}$ contains two experimental parameters: $\mathrm{C}_{\mathrm{v}}$ and $\mathrm{F}^{\mathrm{exp}}$. Parameter $\mathrm{C}_{\mathrm{v}}$ accounts for the quadratic term, whereas parameter $F$ accounts for the linear term. These parameters will be determined from experiments by plotting the experimental values $\Delta \mathrm{P} / \mathrm{Q}^{2}$ as a function of $1 / \mathrm{Q}$ for the single liquid phase data. A linear evolution is then expected, from which a semi-empirical $\mathrm{Q}_{\text {cav }}^{\bullet}$ value, calculated from Eq. (16) but with $\mathrm{F}^{\mathrm{exp}}$, will be compared to the experimental cavitating flow rate. A semiempirical $\sigma_{\text {cav }}^{\bullet}$ value will be determined in a similar way from $\mathrm{F}^{\mathrm{exp}}$.

\section{Role of solid micro- and nanoparticles}

Small inhomogeneities in the liquid may influence the cavitation inception. As said in the Introduction, gaseous voids attached to the irregularities of a solid particle may grow up when the pressure inside is sufficiently low. The pressure $\mathrm{P}_{\mathrm{b}}$ inside a gaseous cavity of mean radius of curvature R obeys

$$
P_{b}=P+\frac{2 \gamma}{R}
$$

where $\mathrm{P}$ is the pressure of the surrounding liquid water, and $\gamma=70 \mathrm{mN} / \mathrm{m}$ is the surface tension of water. The experiments presented here have been performed with filtered (filter porosity $=1 \mu \mathrm{m}$ ) DI water. The condition $\mathrm{P}_{\mathrm{b}}<\mathrm{P}_{\mathrm{vap}}$ with $\mathrm{R} \approx 1 \mu \mathrm{m}$ corresponds to $\mathrm{P} \approx-1.4$ bars. So, when increasing the flow rate from a single liquid phase, a delay in the inception of cavitation is likely to occur with DI water, and the onset of cavitation is expected at $Q>Q_{\text {cav }}$. Adding nanoparticles in the liquid should be of no effect, because the condition $\mathrm{P}_{\mathrm{b}}<\mathrm{P}_{\mathrm{vap}}$ with $\mathrm{R} \approx 20 \mathrm{~nm}$ corresponds to $\mathrm{P} \approx-70$ bars. So, it is obvious that the role of residual microparticles should be predominant since cavitation should have occurred before reaching these highly negative values of static pressure.

\section{EXPERIMENTAL SET UP}

\section{A. Device fabrication}

Our experiments were performed with hybrid siliconPyrex micromachined devices. The steps leading to the microfabrication of the devices (micro-diaphragm or microventuri) fall into three main phases. We start from doubleside polished $350 \mu \mathrm{m}$ thick $\langle 100\rangle$ silicon wafers. The first step is the transfer onto the silicon of the whole structure of the channel. The second one is the deep reactive ion etching of the channel. The third one is the anodic bonding between the etched silicon substrate and a $300 \mu \mathrm{m}$ thick Pyrex substrate with two drilled holes located in front of the inlet and outlet tanks machined into the silicon substrate.

The first step was processed by a classical ultraviolet lithography process. It is sufficient to spread a positive photoresist onto the bare silicon side to perform channels with 
smooth surface silicon at the bottom. The deep reactive ion etching of the samples is based on a Bosch process (alternation of etching and passivation of the walls by $\mathrm{SF}_{6}-\mathrm{C}_{4} \mathrm{~F}_{8}$ plasma) with an etch rate of a few $\mu$ m per minute. That gives way to scalloping on the walls with a spatial period of a few nanometers. Fig. 3(a) is a SEM micrograph of a microdiaphragm. Fig. 3(b) is a SEM micrograph of the input of a micro venturi. As the parameters $\mathrm{w}, \mathrm{W}$, and $\mathrm{H}$ are of primary importance, a SEM observation was performed for each device in order to accurately measure these parameters. As the anisotropic etching is never perfect, a slight deviation from vertical walls was observed. It was taken into account, by determining the effective average values of $\mathrm{W}$ and of $\mathrm{w}$. At last, the anodic bonding of a Pyrex cap is performed by applying a negative voltage $(-500 \mathrm{~V})$ to the Pyrex at around $300^{\circ} \mathrm{C}$. Hydraulic connections are made following a wellsuited method developed previously for microfluidic experiments and published elsewhere. ${ }^{26}$

Most of the devices have the shape displayed in Fig. 1. With these geometries, it is not possible to reach experimental static pressures except $\mathrm{P}_{\text {in }}$ and $\mathrm{P}_{\text {out }}$. To verify the order of magnitude of $\mathrm{P}_{1}$ and $\mathrm{P}_{3}$, we have designed devices with perpendicular grooves included on both sides of the diaphragms.

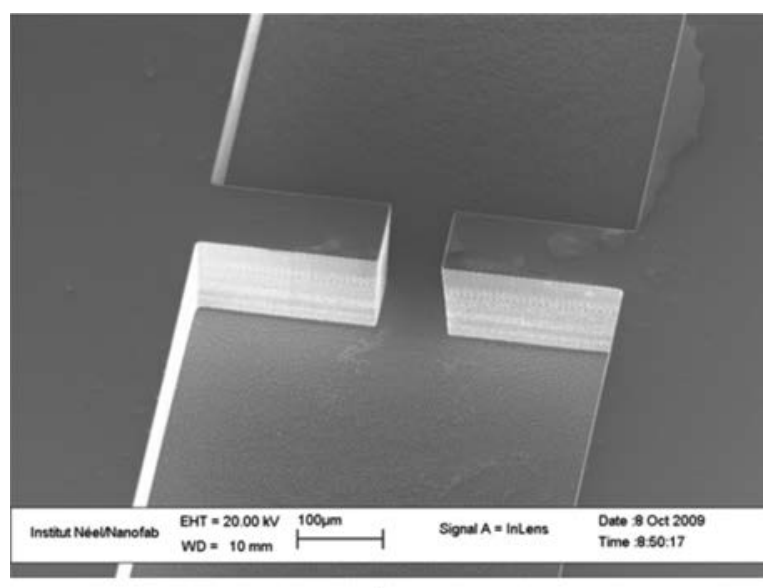

a)

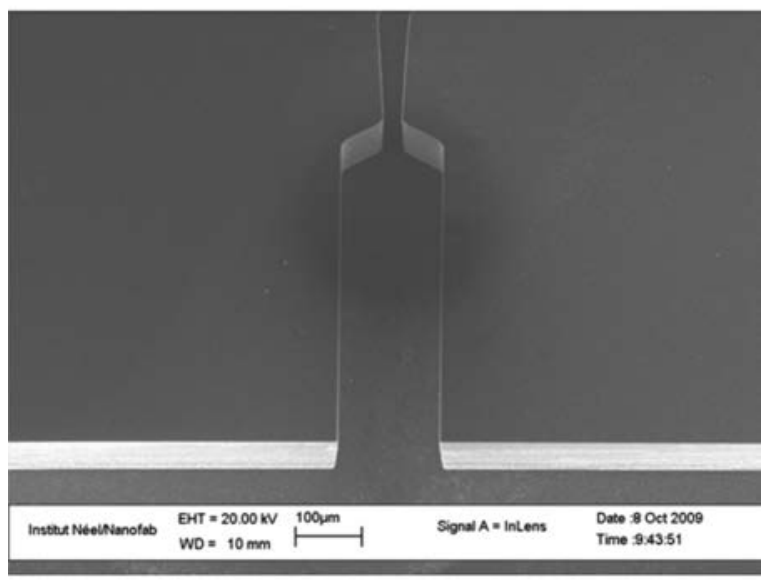

b)

FIG. 3. SEM micrographs of silicon devices with smooth surfaces obtained by reactive ion etching. (a) micro-diaphragm and (b) micro venturi.
The grooves were connected to pressure transducers and gave local data close to $\mathrm{P}_{\text {in }}$ and $\mathrm{P}_{\text {out }}$ and in a good agreement with expected values. That is consistent with the validity of the law of hydrodynamics at microscale. ${ }^{21,22}$

Other variants in the design and fabrication of the devices were related to optical observations. The hybrid $\mathrm{Si}--$ Pyrex devices are not optically transparent, and that may be troublesome for high speed camera imaging. For such applications, which will be presented in a forthcoming paper, we have performed double anodic bonded Pyrex-silicon-Pyrex devices. In these particular devices, a thinned silicon foil is first bonded onto a Pyrex cap, then the channel is etched through the whole thickness of the silicon, and then another Pyrex cap is bonded onto the free silicon side to assure the tightness.

No change in the onset of cavitation was observed when working either with Si-Pyrex or Pyrex-Si-Pyrex devices, since the smoothness of the bottom of etched silicon grooves has the same order of magnitude as that of Pyrex.

\section{B. Experimental apparatus}

The experimental apparatus used to perform the hydrodynamic experiments presented in this paper is shown in Fig. 4. We made the choice to work at a fixed $\mathrm{P}_{\text {out }}$ value and to drive the flow rate by increasing the input pressure $\mathrm{P}_{\text {in }}>\mathrm{P}_{\text {out }}$. The liquid flows from the inlet to the outlet tank through the device under test (DUT). The required pressures $\mathrm{P}_{\text {in }}$ and $\mathrm{P}_{\text {out }}$ are imposed using either pressurized nitrogen and a regulator or a vacuum pump for pressure levels below $\mathrm{P}_{\mathrm{atm}}$. The liquid is filled inside the 8 liter in volume flexible butyl membranes inside the tanks. These membranes prevent from some dissolution of the nitrogen gas inside the liquid. The volume inside the membranes is high enough, so that small fluctuations of pressure during the experiments are negligible because of the relatively low flow rates involved. The flow rate and the pressure at the inlet and outlet of the microchannel are recorded by a thermal mass flow meter (Brooks Flomega 5892) and by two Keller 33-X pressure transducer, respectively. A $1 \mu \mathrm{m}$ sized filter prevents large particles from clogging the channel. The flow through the diaphragm or through the throat of the venturi is observed with a Leica S8 APO stereomicroscope. The rate of dissolved $\mathrm{O}_{2}$ in deionized (DI) water was measured with a Orion 3 Star RDO oxymeter. No-degassed DI water displayed the expected rate of $8 \mathrm{ppm} \mathrm{O}_{2}$. When pumped and mixed during several hours under a primary vacuum, the rate falls down to around $3 \mathrm{ppm} \mathrm{O}_{2}$.

For experiments performed at $\mathrm{P}_{\text {out }}=\mathrm{P}_{\text {atm }}$, it was also possible to connect the output circuitry to a precision balance $( \pm 0.001 \mathrm{~g})$ to weigh the water delivery and to confirm the flow-rate measurements.

Experimental uncertainties are related to geometrical sizes of the channels $(2 \%)$, flow rate measurements $(1 \%)$, pressure transducers (within 1\%). As a consequence, the highest level of uncertainty $(6 \%)$ will be associated with the calculation of $\sigma$, from Eq. (8) as well as from Eq. (17). Errors' bars will not be reported for other data, because included in the size of the spots. 


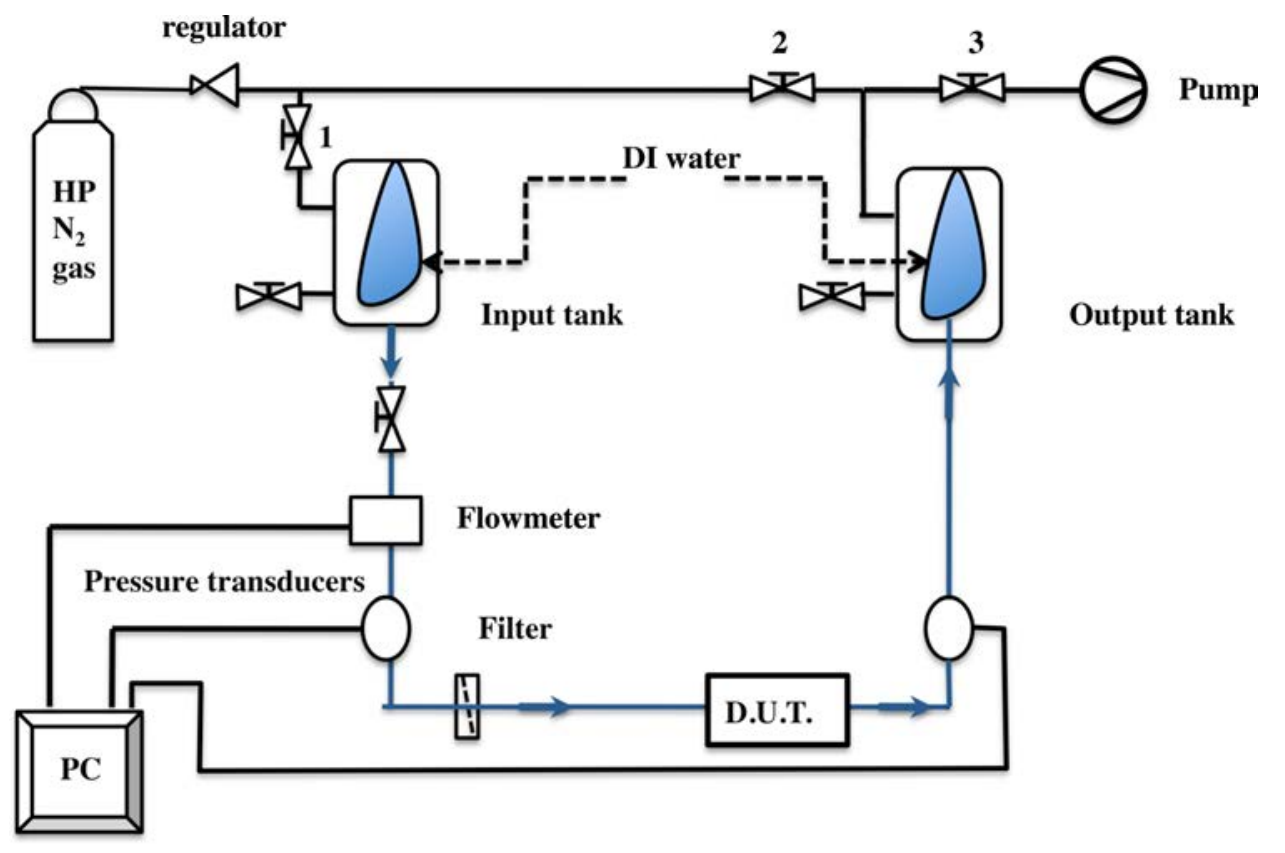

FIG. 4. (Color online) Experimental set up used for the hydrodynamic characterization of each DUT. The liquid flow was monitored by high pressure nitrogen gas. There was no direct contact between the gas and the liquid, to prevent from any unwanted gaseous dissolution.

\section{RESULTS AND DISCUSSION}

\section{A. Micro-diaphragms}

\section{De ionized water and output at atmospherical pressure}

Six different microdiaphragms with smooth surfaces have been tested, and all the devices displayed the same general behaviour detailed below.

By increasing the inlet pressure, the experimental relationship $\Delta \mathrm{P}(\mathrm{Q})$ in the single liquid phase obeys a quadratic evolution. Using Eq. (1), one may find for each sample the experimental values of both the discharge coefficient $C_{d}^{\exp }$ and the contraction coefficient $\mathrm{C}_{\mathrm{c}}$. The single liquid phase in the diaphragm withstands flow rates higher than the threshold value $\mathrm{Q}_{\text {cav }}^{\text {theo }}$ calculated from Eq. (5), which corresponds to a minimum pressure equal to the vapor pressure. That confirms that de-ionized water is able to sustain a metastable liquid phase at $\mathrm{P}<\mathrm{P}_{\text {vap }}$. Still when increasing the inlet pressure, cavitation occurs suddenly and due to the vapor phase, the flow rate falls down. Such a transition is noticeable, because it is very noisy, and vapor pockets downstream the diaphragm are clearly observable. By increasing the inlet pressure in the cavitating regime, there is still an increase of the flow rate, but with a reduced slope due to a smaller value of the contraction coefficient $\mathrm{C}_{\mathrm{c}}$.

The critical flow rates at which the cavitation occurred for a given channel, although being always above $\mathrm{Q}_{\text {cav }}$, could randomly change from an experimental run to another. Cavitation occurs either suddenly or following any external perturbation (as a mechanical vibration on the set up, for example). As we never could observe any individual bubbles before each transition, we cannot define an incipient cavitation number.

Desinent cavitation was scrutinized by decreasing the inlet pressure. The experimental desinent cavitation number was defined at the crossing between the cavitating curve and the single liquid phase $\Delta \mathrm{P}(\mathrm{Q})$ curve, respectively. Desinence is well stated when the vapor pockets and the noise are no more noticeable, and when the flow rate recovers the value it had in the single liquid phase flow. The vanishing of the two-phase flow was in fact characterized by the vanishing of the noise and of the vapor clouds. That occurs at flow rates below $\mathrm{Q}_{\mathrm{cav}}$ that means at $\sigma_{\mathrm{des}}^{\exp }>\sigma_{\text {cav }}$. Sometimes, although cavitation has disappeared, the flow rate does not recover its noncavitating value and is slightly smaller than the expected ones, for a given value of the pressure drop $\Delta \mathrm{P}$. This comes from unsteady thin twin pockets which are attached to the exit of the diaphragm. These pockets are not vapor cavities but are actually due to the accumulation of non-condensable gas trapped in the two separated regions downstream the diaphragm. They are easily removed by turning off and on the valve located upstream the channel (Fig. 4).

The experimental relationship $\Delta \mathrm{P}(\mathrm{Q})$ for a diaphragm of height $\mathrm{H}=101 \mu \mathrm{m}$, width $\mathrm{w}=58 \mu \mathrm{m}$, fed with DI water, is displayed in Fig. 5. The data in the single liquid phase obey Eq. (1) with an average discharge coefficient $\mathrm{C}_{\mathrm{d}}=0.85$. Fig. 6 displays the evolution of $\mathrm{C}_{\mathrm{d}}$ calculated for each individual experimental data. It appears that the average value $\mathrm{C}_{\mathrm{d}}=0.85$ holds for most of the data, except at small flow rates. As mentioned above, $\mathrm{C}_{\mathrm{d}}$ depends on the Reynolds number in the diaphragm, because the length of the orifice is not negligible compared to $\mathrm{d}_{\mathrm{H}}$. The experimental data agree with the expected ones. ${ }^{25}$ The slight shift between experimental and tabulated data in Fig. 6 comes from the fact that the former corresponds to $\mathrm{w} / \mathrm{W}=0.11$ and the later corresponds to $\mathrm{w} / \mathrm{W}=0.20$. From Fig. 5, it can be seen that the single liquid phase in the diaphragm withstands high flow rates above the threshold value $\mathrm{Q}_{\mathrm{cav}}^{\text {theo }}=159 \mu \mathrm{l} / \mathrm{s}$ (corresponding to $\sigma_{\mathrm{cav}}=0.27$ ) calculated from Eq. (5). Cavitation occurs suddenly (A), when $\sigma=0.12$ due to the vapor phase, the flow rate falls down. Variations of the flow rate in the cavitating flow regime are represented with red filled circle points in Fig. 5. The 


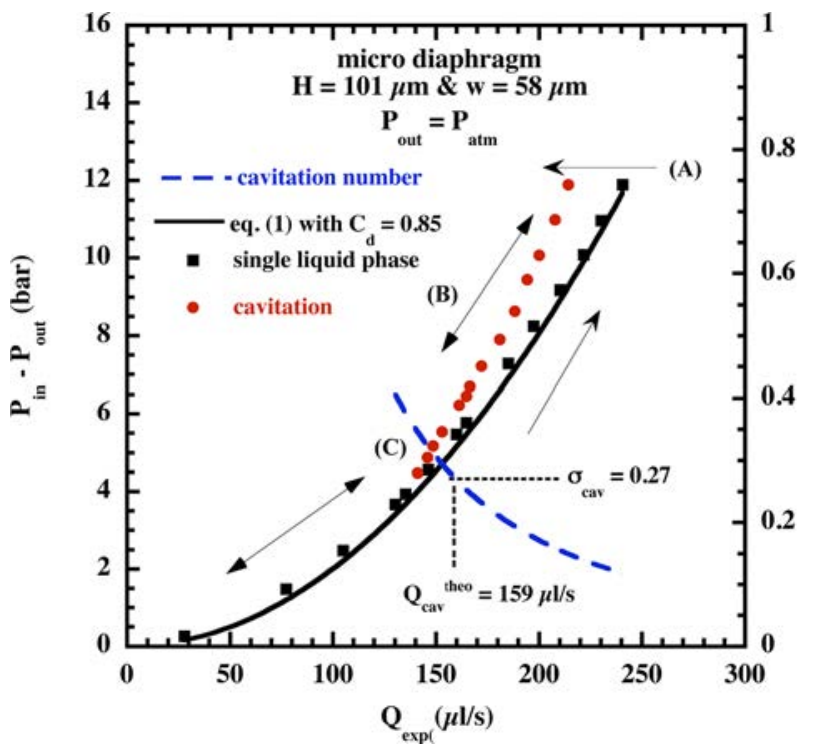

FIG. 5. (Color online) Experimental relationship between the pressure drop across a microdiaphragm and the flow rate, and (dashed line) evolution of the cavitation number. Measurements were performed at $\mathrm{P}_{\text {out }}=\mathrm{P}_{\mathrm{atm}}$. By increasing the pressure drop, the flow rate increases obeying Eq. (1), and withstands a metastable single liquid phase when $\mathrm{Q}>\mathrm{Q}_{\text {cav }}^{\text {theo }}$. The pressure at the vena contracta is then expected to be below $\mathrm{P}_{\text {vap. }}$ A sharp transition occurs suddenly $((\mathrm{A}) \rightarrow(\mathrm{B}))$ and vapor clouds downstream the orifice lower the flow rate. The cavitating data are plotted with red filled circles points. When lowering $\mathrm{P}_{\text {in }}-\mathrm{P}_{\text {out }}$, the size of vapour clouds decreases, but they remain down to flow rates slightly below $\mathrm{Q}_{\mathrm{cav}}$, and the cavitating flow disappears at $\sigma>\sigma_{\text {cav }}$.

discharge coefficient in such a two-phase flow is then $\mathrm{C}_{\mathrm{d}}^{\exp }=0.79$, corresponding to a cavitating flow rate $\mathrm{Q}_{\text {cav }}^{\text {theo }}=153 \mu \mathrm{l} / \mathrm{s}$ and $\sigma_{\text {cav }}=0.29$. We find an experimental desinent number $\sigma_{\text {des }}^{\exp }=0.35$ which is higher than $>\sigma_{\text {cav }}$ $\in[0.27 ; 0.29]$.

Such a behaviour has been observed for all the samples under test. The experimental results are summarized in Table I. Several experiments have demonstrated the reproducibility of the hysteresis behaviour (A)-(B)-(C). A general scope of the behaviour of diaphragms with smooth surfaces is displayed in Fig. 7, where the cavitation number $\sigma$ calculated from Eq. (8) has been plotted as a function of $\mathrm{Re}_{\mathrm{d}}$ for four samples. The empty circles indicate single liquid phase flows, whereas the data corresponding to cavitation are plotted with filled symbols. For each device, the overlap of empty and filled symbols is the signature of the hysteresis. The arrows are guidelines to recall the $\sigma_{\text {cav }}$ value calculated from Eq. (9) with a discharge coefficient $\mathrm{C}_{\mathrm{d}}$ averaged from the experimental values deduced from both the single liquid and two-phase flows. It is obvious that stretched water could flow without any cavitation even if the pressure downstream is below $\mathrm{P}_{\mathrm{vap}}$ $\left(\sigma<\sigma_{\text {cav }}\right)$. Focusing on the device with $\mathrm{w}=81 \mu \mathrm{m}$ in width and $\mathrm{H}=146 \mu \mathrm{m}$ in height, Fig. 7 demonstrates that liquid water could flow up to $\mathrm{Re}_{\mathrm{d}} \approx 3800$; from Eq. (4), that means that a negative pressure $\mathrm{P}_{2} \approx-1.5$ bars exists in the liquid just before the transition to cavitation occurs. However, once the cavitation takes place, the multiphase regime remains as long as $\Delta \mathrm{P}$ is decreased continuously until $\mathrm{P}_{2} \geq \approx \mathrm{P}_{\text {vap. Such }}$ metastable states were observed with degassed DI water $\left(3 \mathrm{ppm} \mathrm{O}_{2}\right)$ as well as with no-degassed DI water $\left(8 \mathrm{ppm} \mathrm{O}_{2}\right)$.

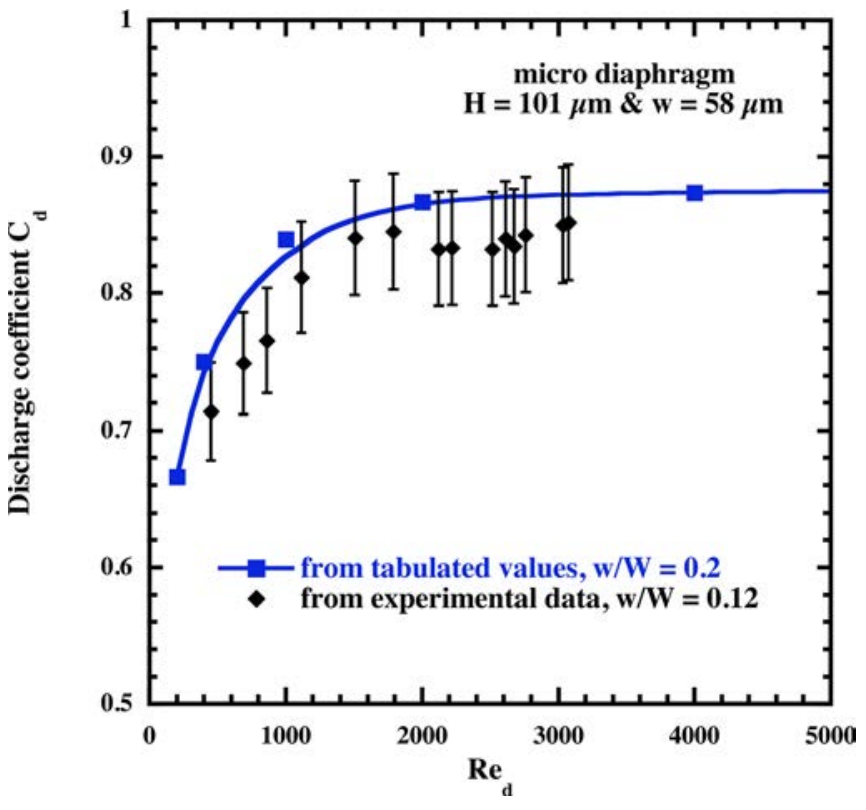

FIG. 6. (Color online) Comparison between tabulated values of the discharge coefficient $\mathrm{C}_{\mathrm{d}}$ and the experimental ones calculated from the data plotted in Figure 5. The evolution of $\mathrm{C}_{\mathrm{d}}$ with the Reynolds number in the diaphragm $\left(\operatorname{Re}_{\mathrm{d}}\right)$ is due to the fact that the length 1 of the orifice is not negligible in front of the hydraulic diameter of the diaphragm $\mathrm{d}_{\mathrm{H}}$. Reprinted with permission from I. E. Idelchik, Handbook of Hydraulic Resistance (Hemisphere, New York, 1986). Copyright 1986 by Hemisphere.

The rate of dissolved $\mathrm{O}_{2}$ gas had no influence on the above behaviour in the quite limited range presently investigated (3-8 ppm).

A possible explanation of our results should be that as transitions towards cavitation occur only when $\operatorname{Re}_{\mathrm{d}}>2000$, cavitation should be the consequence of enhanced interactions between the liquid and the walls of the diaphragm, nearby the turbulent transition. However, such an explanation does not hold with former results ${ }^{18}$ obtained with different micro sized diaphragms at $\operatorname{Re}_{\mathrm{d}}<2000$. Thus, we believe that DI water gives rise to a metastable liquid phase in the diaphragm and in eddies at the exit of the orifice, because of (1) the lack of bulk nuclei, (2) the lack of surface nuclei due to the very small roughness of the walls, and (3) the small residence time which limits the time available for bubble growth. When nucleation occurs, vapor pockets grow at the exit of the orifice, and there is a decrease of the flow and a small change of the contraction coefficient. Once bubbles have been created, they are kept up by eddies in the two shear layers which are developing at the exit of the diaphragm. Eddies create low-pressure cores at pressures $\mathrm{P}<\mathrm{P}_{2}$ where bubbles can growth even if $\mathrm{P}_{2}$ is above $\mathrm{P}_{\mathrm{vap}}$. This explains why all the devices have displayed $\sigma_{\text {des }}^{\text {exp }} \geq \sigma_{\text {cav }}$.

These results are coherent with the unique reference related to similar work, ${ }^{18}$ where the authors observed a strong cavitation hysteresis between a low incipient cavitation number and a rather high desinent cavitation number. That is still consistent with the concept of unsteady vapor pocket trapped in low pressure cores downstream the diaphragm. Concerning the lack of influence of the oxygen dissolved level; we believe that the two values tested in the present work ( 8 and $3 \mathrm{ppm}$ ) are too much similar from each 
TABLE I. Characteristics of 6 diaphragms tested with deionized water. H: height of the channel; w: width of the diaphragm; $\mathrm{d}_{\mathrm{H}}$ : hydraulic diameter of the diaphragm. Both values of the discharge coefficient $\mathrm{C}_{\mathrm{d}}$ experimentally recorded in the single liquid and two-phase flow, respectively, are reported. The corresponding values of the contraction coefficient $\mathrm{C}_{\mathrm{c}}$ (Eq. (7)), the cavitation flow rates $\mathrm{Q}_{\text {cav }}$ (Eq. (5)), the critical cavitation numbers $\sigma_{\text {cav }}($ Eq. (9)) are reported. The experimental cavitation flow rates and their related cavitation number are related to the desinence of cavitation.

\begin{tabular}{|c|c|c|c|c|c|c|c|c|}
\hline $\mathrm{H}(\mu \mathrm{m})$ & $\mathrm{w}(\mu \mathrm{m})$ & $\mathrm{d}_{\mathrm{H}}(\mu \mathrm{m})$ & $\mathrm{C}_{\mathrm{d}}^{\exp }$ & $\mathrm{C}_{\mathrm{c}}^{\exp }$ & $\mathrm{Q}_{\text {cav }}^{\text {theo }}(\mu \mathrm{l} / \mathrm{s})$ & $\mathrm{Q}_{\text {cav }}^{\exp }(\mu \mathrm{l} / \mathrm{s})$ & $\sigma_{\mathrm{cav}}$ & $\sigma_{\text {des }}^{\exp }$ \\
\hline 101 & 58 & 74 & $0.85 \backslash 0.79$ & $0.78 \backslash 0.72$ & $159 \backslash 153$ & 142 & 0.270 .29 & 0.35 \\
\hline 101 & 80 & 89 & $0.80 \backslash 0.74$ & $0.71 \backslash 0.67$ & $180 \backslash 173$ & 170 & $0.39 \backslash 0.42$ & 0.44 \\
\hline 126 & 60 & 81 & $0.93 \backslash 0.89$ & $0.84 \backslash 0.80$ & $210 \backslash 205$ & 184 & $0.25 \backslash 0.26$ & 0.34 \\
\hline 126 & 81 & 99 & $0.81 \backslash 0.76$ & $0.72 \backslash 0.68$ & $228 \backslash 221$ & 222 & $0.39 \backslash 0.42$ & 0.42 \\
\hline 134 & 63 & 86 & $0.80 \backslash 0.77$ & $0.73 \backslash 0.70$ & $213 \backslash 209$ & 200 & $0.31 \backslash 0.32$ & 0.37 \\
\hline 146 & 81 & 104 & $0.81 \backslash 0.75$ & $0.72 \backslash 0.67$ & $264 \backslash 254$ & 234 & $0.39 \backslash 0.42$ & 0.49 \\
\hline
\end{tabular}

other to draw any conclusion. With values in the same order of magnitude, Mishra and Peles ${ }^{18}$ noticed only a slightly expected delay in the inception of cavitation when the $\mathrm{O}_{2}$ concentration was lowered, and they did not notice any effect on other parameters.

\section{Variable output pressures}

Complementary experiments were conducted at different fixed output pressures $\mathrm{P}_{\text {out }}$, with the devices $\mathrm{A}=[\mathrm{H}=101$ $\mu \mathrm{m}, \mathrm{w}=80 \mu \mathrm{m}]$ and $\mathrm{B}=[\mathrm{H}=126 \mu \mathrm{m}, \mathrm{w}=60 \mu \mathrm{m}]$. The single liquid flow obeys Eq. (1) with $\mathrm{C}_{\mathrm{d}}=0.8$ for sample $\mathrm{A}$ and $\mathrm{C}_{\mathrm{d}}=0.93$ for sample $\mathrm{B}$, whatever the output pressure is. A strong hysteresis behaviour still occurs, and when the cavitating flow is established, the $\Delta \mathrm{P}(\mathrm{Q})$ relationship does not depend on $\mathrm{P}_{\text {out }}$. The flow rates at which the desinence of cavitation occurs depend on $\mathrm{P}_{\text {out }}$; however, they do not obey

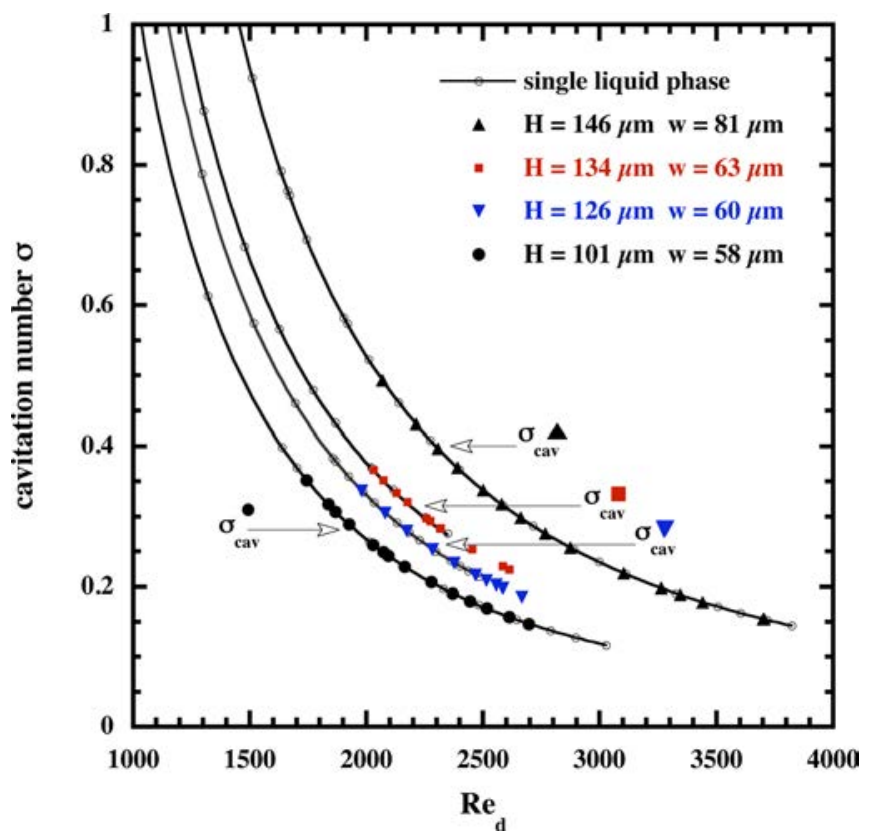

FIG. 7. (Color online) Cavitation number plotted as a function of the Reynolds number in the diaphragm for 4 different samples with smooth surfaces. The empty circles correspond to the single liquid phase flow, and the filled symbols correspond to cavitating flows. The overlap of the two regimes is the consequence of the delay in the inception of cavitation and of the hysteretis behaviour. The specific arrows correspond to the $\sigma_{\text {cav }}$ value calculated from Eq. (9). It can be seen that the effective desinence of cavitation occurs for cavitation numbers slightly above $\sigma_{\text {cav }}$.
Eq. (5). These flow rates are below the expected ones. That is, summarized in Fig. 8 for the device A, where the cavitation number is plotted as a function of $\operatorname{Re}_{\mathrm{d}}$ for the different output pressures. An increase of $\sigma_{\text {des }}^{\exp }$ when $\mathrm{P}_{\text {out }}$ increases is clearly noticeable.

The conclusions we may draw from the results plotted in Fig. 8 are as follows. The transition from a single liquid phase flow to a cavitating flow regime may be strongly and randomly delayed, once a negative pressure exerts on DI water flowing through the smooth micro diaphragms. It is definitely in agreement with the presence of a liquid metastable state. When the cavitating flow regime is established, the desinence of cavitation depends strongly on the Reynolds number, and does not display any random character. Condensation of vapour clouds downstream the diaphragm is anomalously delayed when increasing the static pressure at the vena contracta.

These results may be the consequence of the use of DI water flowing through devices of reduced size with smooth walls. A typical order of magnitude of the average velocity of the fluid through the diaphragm when $\mathrm{Q}=\mathrm{Q}_{\text {cav }}$ is $\approx 20 \mathrm{~m}$ $\mathrm{s}^{-1}$, so that the shear rate of the flow downstream is around $10^{5} \mathrm{~s}^{-1}$. To get a better understanding of the tensile strength of water in such conditions, we have performed the same experiments but with water loaded with nanoparticles acting as solid nuclei in the liquid.

\section{Cavitation of nanofluids}

Similar experiments have been performed with the smooth diaphragm of height $\mathrm{H}=126 \mu \mathrm{m}$ and width $\mathrm{w}=60$ $\mu \mathrm{m}$ (sample B) fed with dilute nanofluids. Gadolinium nanoparticles functionalized with a $\mathrm{SiO}_{2}$ hydrophilic shell were dilute in DI water as the base fluid. TEM photographs of that sort of nanoparticles are available in Ref. 27. The size of the nanoparticles is $2-3 \mathrm{~nm}$ in diameter, and the solid volume concentration $\phi$ of the nanofluids tested was $\phi=10^{-5}$, $\phi=7 \times 10^{-5}$, and $\phi=10^{-4}$. However, it is established that nanoparticles form aggregates that give way to an apparent solid volume concentration $\phi_{\mathrm{a}}$ higher than the calculated one. $^{28,29}$ From the conclusions of former works on the rheology of nanofluids flowing through microchannels, ${ }^{30}$ we can estimate for the present experiments an average diameter of a single aggregate around $25 \mathrm{~nm}$, and an apparent solid volume concentration $10^{-4}<\phi_{\mathrm{a}}<10^{-3}$. Such a range of $\phi_{\mathrm{a}}$ is low enough, so that it is of negligible influence on the density and 


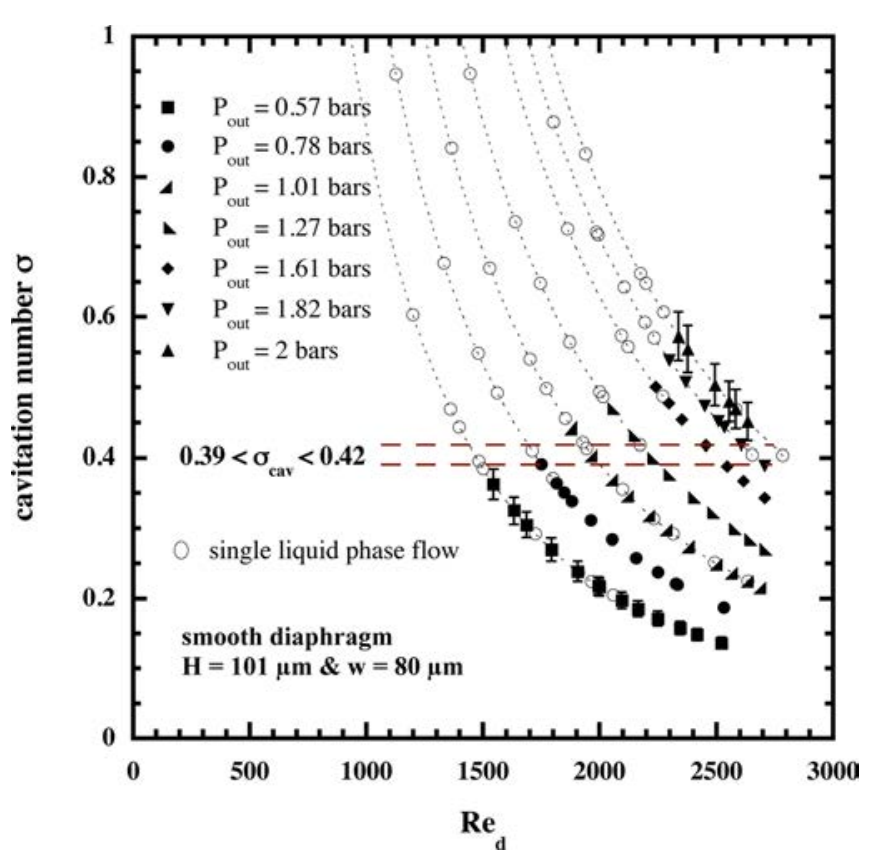

FIG. 8. (Color online) Arrays of $\sigma\left(\mathrm{Re}_{\mathrm{d}}\right)$ curves recorded at different fixed $\mathrm{P}_{\text {out }}$ values, for a micro diaphragm fed with DI water. The empty circles correspond to the single liquid phase flow, and the filled symbols correspond to cavitating flows. Although the desinence of cavitation is expected to depend only on the shape of the diaphragm, it depends strongly on the Reynolds number in the diaphragm.

on the viscosity of the fluid. Compared to pure DI water, cavitation with nanofluids arises in a softened way: the shift of the flowrate and the intensity of the noise are weaker. With the very dilute nanofluid, $\left(\phi=10^{-5}\right)$, it is still possible to withstand negative pressures when $\mathrm{Q}>\mathrm{Q}_{\mathrm{cav}}=210 \mu \mathrm{l} / \mathrm{s}$, and cavitation occurs at $\mathrm{Q} \approx 240 \mu \mathrm{l} / \mathrm{s}$. However, the nanofluid with a concentration ten times higher does not exhibit any hysteretic behaviour. The relationship between the pressure

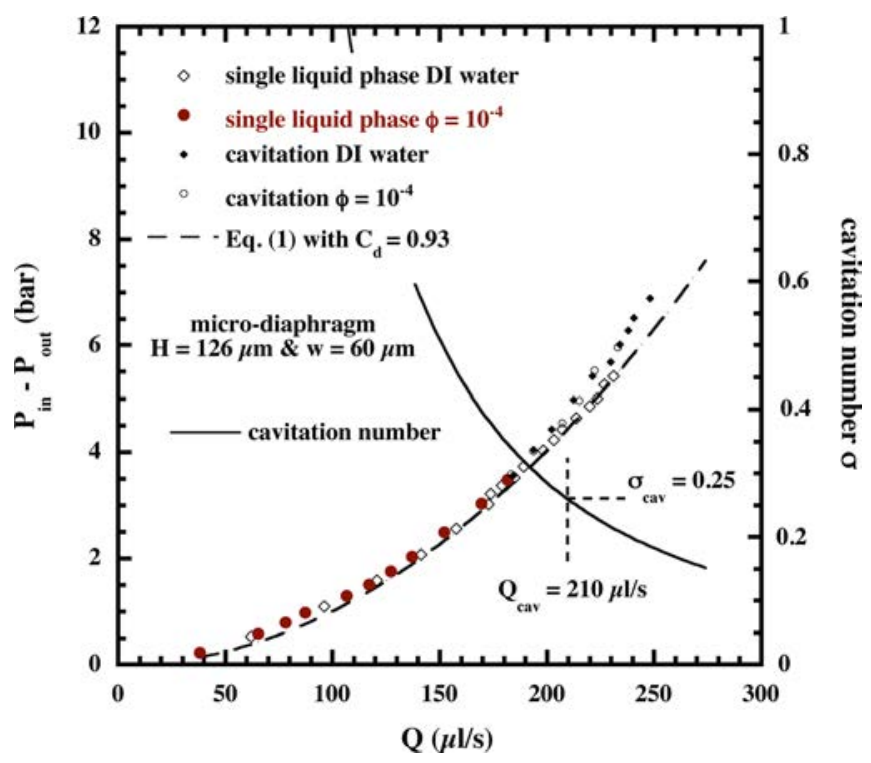

FIG. 9. (Color online) Experimental relationships $\Delta \mathrm{P}(\mathrm{Q})$ performed at $\mathrm{P}_{\text {out }}=\mathrm{P}_{\mathrm{atm}}$, across one microdiaphragm fed with DI water (square symbols) and with a nanofluid owing a solid volume concentration $\phi=10^{-4}$ (circles). Experiments with DI water display a hysteresis behaviour (the single liquid phase remains up to $\mathrm{Q} \approx 240 \mu \mathrm{l} / \mathrm{s}$ ). However, the transition to cavitation is no more delayed with the nanofluid. drop and the flow rate is reported in Fig. 9 for $\phi=10^{-4}$, and is compared to results obtained with pure deionize water. Experiments were conducted at $\mathrm{P}_{\text {out }}=\mathrm{P}_{\mathrm{atm}}$. Cavitation with $\phi=10^{-4}$ occurs just before that the pressure falls below $\mathrm{P}_{\mathrm{vap}}$ at the vena contracta. No hysteretis behaviour is noticeable when $\phi=10^{-4}$. Whatever the solid concentrations are $\left(\phi=0,10^{-5}, 10^{-4}\right)$, the desinence of cavitation takes place around $\mathrm{Q} \approx 180 \mu \mathrm{l} / \mathrm{s}$, that is, a cavitation number (from Eq. (9)) $\sigma \approx 0.35$. The expected cavitation number (calculated from Eq. (10)) is $\sigma_{\text {cav }}=0.25$.

Experiments were then conducted at $\phi=7 \times 10^{-5}$ by varying the output pressure, and the results are compiled in Fig. 10 via a $\sigma\left(\operatorname{Re}_{\mathrm{d}}\right)$ graph. Errors' bars associated with $\sigma$ values are reported only for $\mathrm{P}_{\text {out }}=0.60$ bar and $\mathrm{P}_{\text {out }}=1.52$ bar for a better reading of the data. The hysteretic behaviour is weak and becomes unnoticeable when the fixed value of $\mathrm{P}_{\text {out }}$ is increased. The desinence of the cavitation obeys the same empirical relationship $\sigma_{\mathrm{des}}^{\exp } \approx 0.12+5 \cdot 10^{-3} \cdot R e_{\mathrm{d}}^{1 / 2}$ as with pure DI water.

\section{Discussion}

As a matter of fact, cavitation observed here is a shear type cavitation. Because of the sudden enlargement, a jet is formed at the throat exit. Its border is a region of high shear, where vortices develop. Because of centrifugal forces, the pressure in the core of these vortices is somewhat smaller than the ambient pressure. The pressure drop inside vortices should be added to the conventional pressure drop due to the change of device area, in order to estimate the desinent

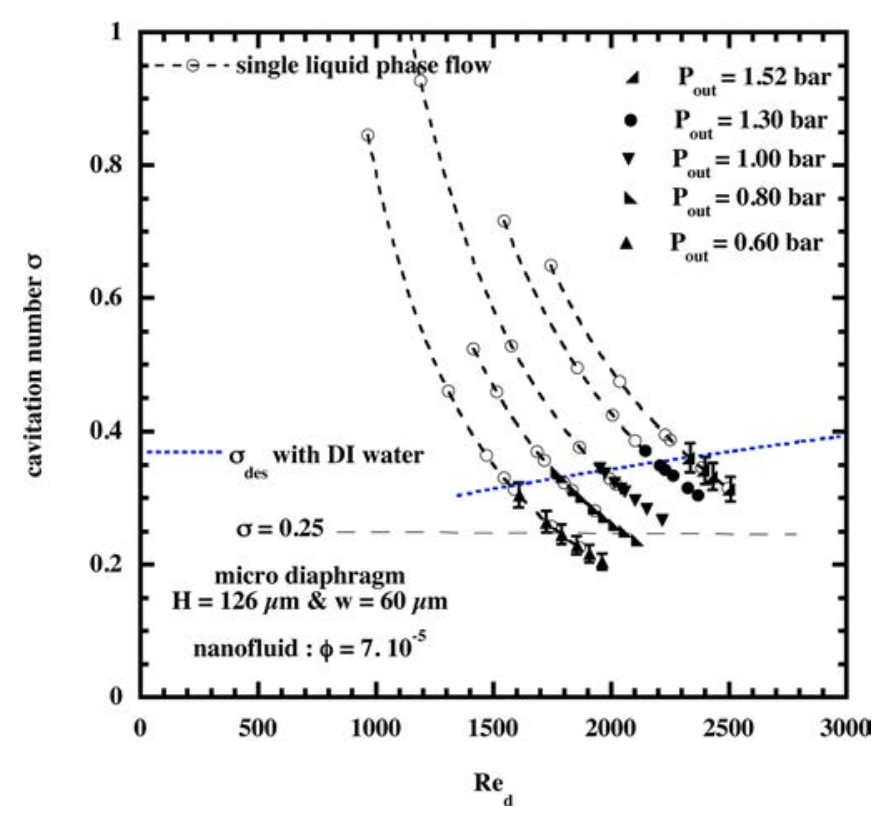

FIG. 10. (Color online) Arrays of $\sigma\left(\operatorname{Re}_{\mathrm{d}}\right)$ curves plotted, for a smooth micro diaphragm fed with a nanofluid with a solid volume concentration $\phi=7 \times 10^{-5}$, at different output pressures. Single liquid phase and cavitating flows are distinguished by the same rules as in Figs. 7 and 8 . The overlap between single liquid and two phase flows curves is dramatically reduced, because of a lack of hysteresis. The transition from a cavitating towards a single liquid phase flow exhibits the same dependence on the output pressure as with pure water. It occurs at a higher cavitation number than the constant value calculated with Eq. (9) from the Bernoulli formalism. The evolution of $\sigma_{\text {des }}^{\exp }$ is fitted by a $\operatorname{Re}_{d}^{1 / 2}$ function as for cavitation in vortical flows. 
cavitation number. As a result, that number should be larger than that given by Eq. (9) which is derived from Bernoulli equation and which takes into account the only change in area. Equation (9) shows that $\sigma_{\text {cav }}$ can be considered as independent of $\mathrm{Re}_{\mathrm{d}}$. However, Arndt ${ }^{31}$ has shown that, by considering the vortical structures, the incipient cavitation number becomes Reynolds dependent. For laminar flow, Arndt's theory predicts a variation of the critical cavitation number as $\mathrm{Re}^{1 / 2}$. Following Arndt's conclusions, it may be conjectured that the Reynolds dependency observed in Fig. 10 is actually due to the coherent vortical structures which develop in the two shear layers at the limit of the jet. The results of our experiments agree with such a model but based on the vanishing of cavitation, when the pressure in eddies raises above $\mathrm{P}_{\mathrm{vap}}$. Vortical structures are related to the influence of the Reynolds number in the vanishing of cavitation. It must be noticed that the vanishing of cavitating flows with pure DI water does not display any random character, contrary to what is observed in the onset of cavitation.

However, the experimental evolution of $\sigma_{\text {des }}^{\exp }$ as a function of $\operatorname{Re}_{\mathrm{d}}$ (Fig. 8) is rather linear for the device with $\mathrm{H}=101 \mu \mathrm{m}$ and $\mathrm{w}=80 \mu \mathrm{m}$, when experiments are performed with pure DI water. Unfortunately that device has broken before collecting a set of data with nanofluids and a comparison is actually not possible. It should be noticed, for that device, that the deviation from a $\operatorname{Re}^{1 / 2}$ evolution of $\sigma_{\mathrm{des}}$ is mainly the consequence of the data recorded at $\operatorname{Re}>2300$. Cavitating flows are perhaps kept up for $\operatorname{Re}>2300$ and as long as the flow does not recover a fully laminar regime.

It is generally stated, that submicron particles have no measurable influence on the onset of cavitation. ${ }^{10}$ Gaseous voids attached to their irregularities cannot grow up, unless exposed to very high tensile strengths. Concerning pure DI water, the application of Eq. (4), using the flow rates corresponding to the onsets of cavitation, gives negative local pressure values, which are in a good agreement with the assumption of micrometer size nuclei. The anomalous effect is that the presence of nano aggregates above a critical solid concentration has lowered the nucleation threshold via another mechanism that the classical growth of attached gas bubbles around lonely particles. With these devices, the onset of cavitation is almost the same as for water "filled to the brim" with the large nuclei. The explanation we suggest is that clusters of nanoparticles (a) are trapped in the core of vortices; (b) interact with each other and; (c) grow up to form aggregates of several micrometers in size, so that the onset of cavitation is no more delayed.
Complementary experiments with micro venturis, which are depicted below, were performed in order to confirm or infirm that explanation, since the sheet cavitation usually observed inside the venturi is free from high shear vortical structures.

\section{B. Micro venturi}

\section{De ionized water and output at atmospherical pressure}

Three micro venturis have been tested with DI water at $\mathrm{P}_{\text {out }}=\mathrm{P}_{\mathrm{atm}}$. Their hydraulic characteristics are summarized in Table II. In these devices, the regular pressure losses expected from the $\mathrm{F}\left(\mathrm{w}_{\mathrm{o}}, \mathrm{w}_{\mathrm{L}}, \mathrm{H}\right)$ function are no more negligible. As noticed above, plotting $\left(\mathrm{P}_{\text {in }}-\mathrm{P}_{\text {out }}\right) / \mathrm{Q}^{2}$ as a function of $1 / \mathrm{Q}$ with the data recorded in the single liquid phase must lead to a straight line, whose slope is related to $\mathrm{F}$ and whose intersection with the vertical axis, when $1 / \mathrm{Q} \rightarrow 0$, is related to $\mathrm{C}_{\mathrm{v}}$. For each device, in the single liquid phase, two flow regimes are noticeable: below flow rates around 50-70 $\mu \mathrm{l} / \mathrm{s}$, the slope is in a good agreement with the numerical data calculated from Eq. (11); above flow rates around 50-70 $\mu \mathrm{l} / \mathrm{s}$, there is a sharp increase of the slope, that is, a consequence of a laminar separation of the liquid from the wall of the channel downstream the throat. These deductions have been confirmed by optical observations and will be discussed in a forthcoming paper.

The previous equations related to venturis assume that no separation occurs in the diffuser. Even though the flow is separated, we assume that the decomposition of the pressure losses as the sum of a linear and a quadratic terms is still valid. The experimental values of parameter $F^{\exp }$ which is found from the tuning procedure explained above is significantly larger than that derived from Eq. (11) (see Table II) and takes into account, to some extent, the separated nature of the flow in the diffuser.

The data recorded for each venturi in the single liquid phase, once laminar separation has occurred, are displayed in Fig. 11, and the corresponding $\mathrm{C}_{\mathrm{v}}$ and $\mathrm{F}^{\mathrm{exp}}$ values are reported in Table II. We get $0.74<\mathrm{C}_{\mathrm{v}}<0.79$ for the three samples, with a constant $\mathrm{C}_{\mathrm{v}}$ value that does not depend on the Reynolds number $\mathrm{Re}_{\mathrm{v}}$ in the range of the flow rates under consideration. As $\mathrm{F}^{\mathrm{exp}}$ is greater than $\mathrm{F}$ nearby the transition towards a cavitating flow regime, the $\mathrm{Q}_{\mathrm{cav}}$ value calculated from Eq. (16) must be reconsidered. In Table II, we give the semi-empirical $\mathrm{Q}_{\mathrm{cav}}^{\bullet}$ and $\sigma_{\text {cav }}^{\bullet}$ values calculated from the $\mathrm{F}^{\exp }$ data obtained from the graphs in Fig. 11.

TABLE II. Characteristics of 3 venturis tested with deionized water. H: height of the channel; $w_{\mathrm{o}}$ : width of the throat; $\mathrm{w}_{\mathrm{L}}$ : width of the output of the diffuser of aperture $\alpha ; \mathrm{d}_{\mathrm{H}}$ : hydraulic diameter of the throat of the venturi. $\mathrm{F}_{\mathrm{exp}}$ and $\mathrm{C}_{\mathrm{v}}$ are obtained from experimental data. The cavitation flow rate and the corresponding cavitation number are calculated from experimental values of the F function. The experimental cavitation flow rates and their related cavitation number are related to the desinence of cavitation.

\begin{tabular}{|c|c|c|c|c|c|c|c|c|c|c|c|}
\hline $\mathrm{H}$ & $\begin{array}{c}\mathrm{w}_{\mathrm{o}} \\
(\mu \mathrm{m})\end{array}$ & $\mathrm{w}_{\mathrm{L}}$ & $\begin{array}{c}\alpha \\
\left({ }^{\circ}\right)\end{array}$ & $\begin{array}{c}\mathrm{d}_{\mathrm{H}} \\
(\mu \mathrm{m})\end{array}$ & $\begin{array}{c}\mathrm{F}(\mathrm{Eq} .(11)) \\
(\mathrm{Pa} \mathrm{s} / \mathrm{m})\end{array}$ & $\mathrm{F}^{\exp }$ & $\mathrm{C}_{\mathrm{v}}$ & $\begin{array}{c}\mathrm{Q}_{\mathrm{cav}}^{\bullet}(\text { Eq. }(16)) \\
(\mu \mathrm{l} / \mathrm{s})\end{array}$ & $\mathrm{Q}_{\mathrm{cav}}^{\exp }$ & $\sigma_{\text {cav }}^{\bullet}($ Eq. (18)) & $\sigma_{\mathrm{des}}^{\exp }$ \\
\hline 127 & 61 & 755 & 4 & 82 & 1389 & 2493 & 0.74 & 154 & 145 & 0.50 & 0.55 \\
\hline 110 & 45 & 654 & 3.5 & 64 & 1869 & 2427 & 0.79 & 97 & 111 & 0.51 & 0.37 \\
\hline 110 & 33 & 640 & 3.5 & 51 & 1999 & 3163 & 0.77 & 79 & 79 & 0.42 & 0.41 \\
\hline
\end{tabular}




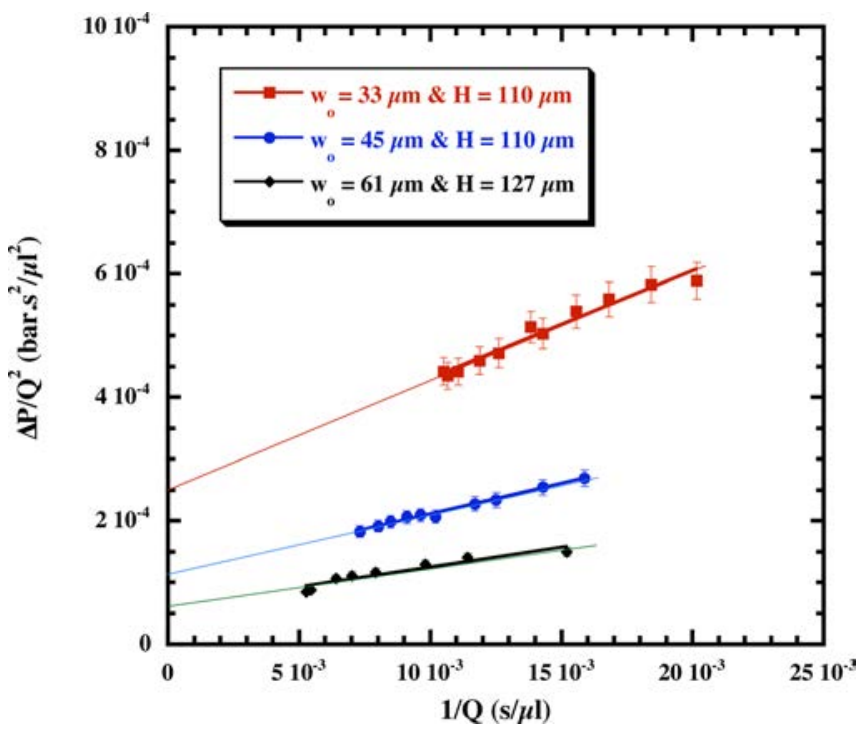

FIG. 11. (Color online) Determination of the venturi coefficient $\mathrm{C}_{\mathrm{v}}$ and of the losses in the diffuser, in the single liquid phase flow nearby the transition to cavitation, for 3 microventuris. From Eq. (10), the slopes of the lines give an experimental value $\mathrm{F}_{\text {exp }}$ of the $\mathrm{F}\left(\mathrm{w}_{\mathrm{o}}, \mathrm{w}_{\mathrm{L}}, \mathrm{H}\right)$ function The intersections of the lines with the $\mathrm{Y}$ axis when $1 / \mathrm{Q} \rightarrow 0$ allow the determination of $\mathrm{C}_{\mathrm{v}}$. The results are reported in Table II.

For all the devices under test, the liquid withstands high flow rates without cavitating at $\mathrm{Q}>\mathrm{Q}_{\mathrm{cav}}^{\bullet}$ which corresponds to negative absolute pressures $\mathrm{P}_{\mathrm{o}}$ estimated from Eq. (15) (with $\mathrm{F}^{\mathrm{exp}}$ ) to be ranging from -0.8 bar to -1.5 bar. The transition to cavitating flow arises in a laminar regime, at cavitation numbers around $\sigma=0.25$, well below the calculated $\sigma_{\text {cav }}$ values. The sudden transition gives way to a drop of the flow rate, more important for the device with the larger throat and the larger diffuser aperture. Whatever the sizes of the devices, a vapor attached cavity develops downstream the throat of the venturi. Laminar separation is the consequence of large negative pressure gradients present in the diffuser. In such a case, cavitation nuclei from the main flow are trapped in the recirculation region where they grow and develop into an attached cavity. High frequency imaging (that will be displayed in a forthcoming paper) has demonstrated that the vapor sheet is unsteady, with a periodic shape pulsation. When decreasing the inlet pressure, the size of the vapor cavity is progressively reduced until it disappears, unless an unsteady bubble filled with non-condensable gas remains attached to the wall of the channel. The experimental desinence of cavitation is in a rather good agreement with the Eqs. (16) and (18), when using $\mathrm{F}^{\exp }$.

The relationship $\triangle \mathrm{P}(\mathrm{Q})$ is reported in Fig. 12 for the device with $\alpha=4^{\circ}$. A hysteresis behaviour, similar to what was observed with diaphragms, is present.

\section{Variable output pressures}

A set of data recorded at different output pressures with the venturi $\mathrm{w}_{\mathrm{o}}=45 \mu \mathrm{m}$ and $\mathrm{H}=110 \mu \mathrm{m}$, fed with deionized water is displayed in Fig. 13, where the cavitation number calculated from Eq. (17) is plotted as a function of the Reynolds number in the throat of the venturi. The limits, expected from Eq. (11), are represented by bold dashed curves calcu-

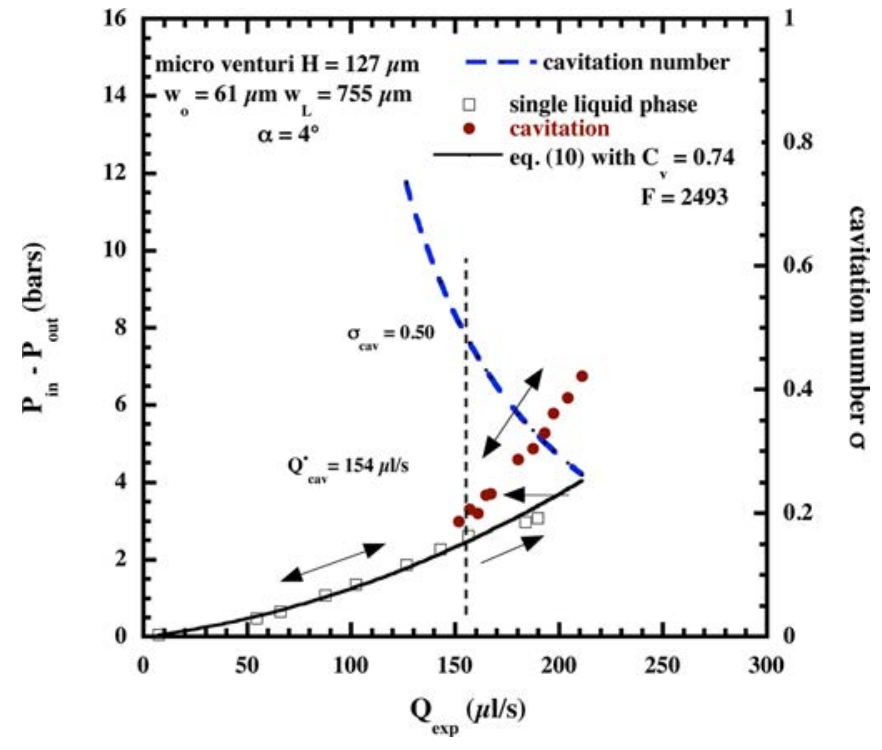

FIG. 12. (Color online) Experimental relationship between the pressure drop across a microventuri and the flow rate, and (dashed line) evolution of the cavitation number. Measurements were performed at $\mathrm{P}_{\text {out }}=\mathrm{P}_{\mathrm{atm}}$. By increasing the pressure drop, the flow rate increases obeying Eq. (10) and withstands a metastable single liquid phase, whereas the pressure at the throat is expected to be below $\mathrm{P}_{\text {vap. }}$ A transition occurs suddenly and a vapor pocket, taking place downstream the throat, lowers the flow rate. The cavitating data are plotted with red filled circles points. When lowering $\mathrm{P}_{\text {in }}-\mathrm{P}_{\text {out }}$, the size of the pocket decreases drastically, and the desinence of cavitation takes place at $\sigma \approx \sigma_{\text {cav }}$.

lated as well with the theoretical $F$ value as with the experimental one. As mentioned above, $\sigma_{\text {cav }}$ is expected to depend on $\mathrm{P}_{\text {out }}$. Such a dependence is obvious, especially when $\mathrm{P}_{\text {out }}<\mathrm{P}_{\mathrm{atm}}$. When decreasing the pressure drop and the flow rate, cavitation stops at $\sigma$ values below the expected ones. It must be noticed that it is rather difficult to state the vanishing of cavitation at low output pressures, because of the large size of the vapor cavity which may spread downstream the diffuser.

\section{Cavitation of nanofluids}

The same types of nanofluids as presented above have been tested with the venturi $\mathrm{H}=110 \mu \mathrm{m}$ and $\mathrm{w}_{\mathrm{o}}=45 \mu \mathrm{m}$. The results are summarized in Fig. 14, and the similarity with the results of Fig. 13, obtained with the same device but with DI water, must be underlined. The presence of nanoparticles in the liquid did not break the hysteresis phenomena and did not change the transition from cavitating to single liquid phase flow. The solid phase is of no influence, neither in the threshold of the cavitation flow nor in the condensation of vapor pockets.

\section{Discussion}

Downstream the throttle of the micro venturis, a cavitation sheet grows from an attached cavity issue from laminar separation of the flow from the walls. High speed camera visualisations, which will be presented in a forthcoming paper, will furnish more informations, about the bubbles shape and its evolution. We confirm that supercavitation develops when the pressure downstream the throat is reduced. ${ }^{20}$ The 


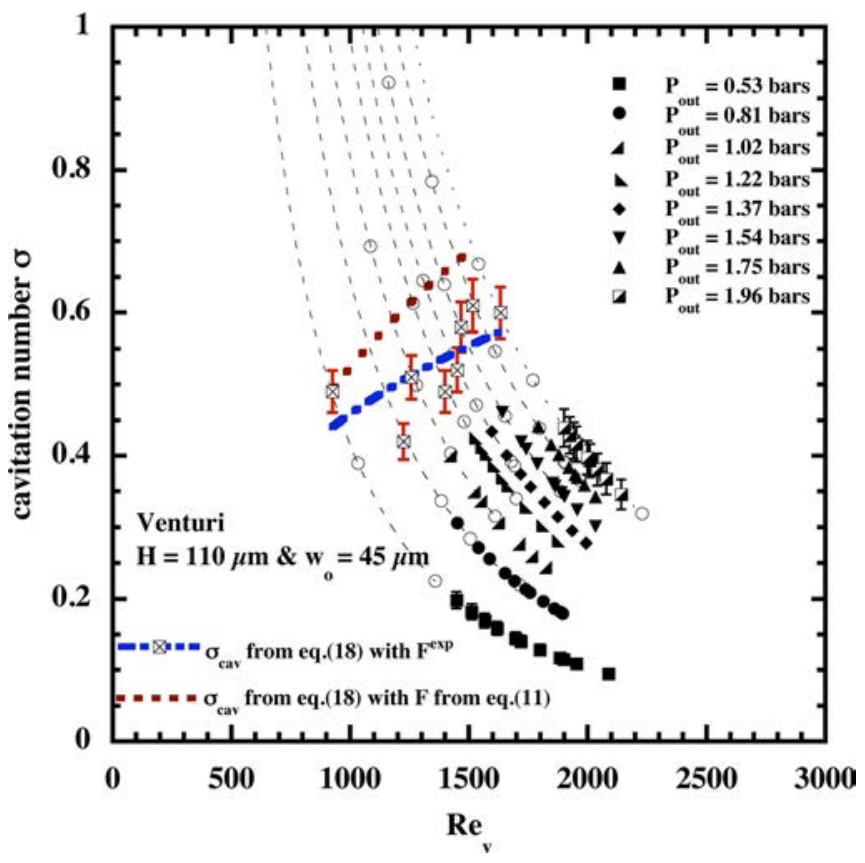

FIG. 13. (Color online) Arrays of $\sigma\left(\operatorname{Re}_{\mathrm{v}}\right)$ curves recorded at different fixed $\mathrm{P}_{\text {out }}$ values, for a micro venturi fed with DI water. The empty circles correspond to the single liquid phase flow, and the filled symbols correspond to cavitating flows. The desinence of cavitation is expected to depend on $\mathrm{P}_{\text {out }}$ and on the losses $\mathrm{F}$ in the diffuser (two dashed lines, the upper comes from calculated values, the lower is averaged from semi-empirical data). The experimental results agree with such an analyse, although desinent cavitation numbers are slightly below the expected ones.

presence of nanoparticles in DI water, with a solid volume concentration up to $\approx 10^{-4}$, had no influence on the cavitation through micro venturis. The ability of these devices to sustain tensile stress limited to small negative pressures is

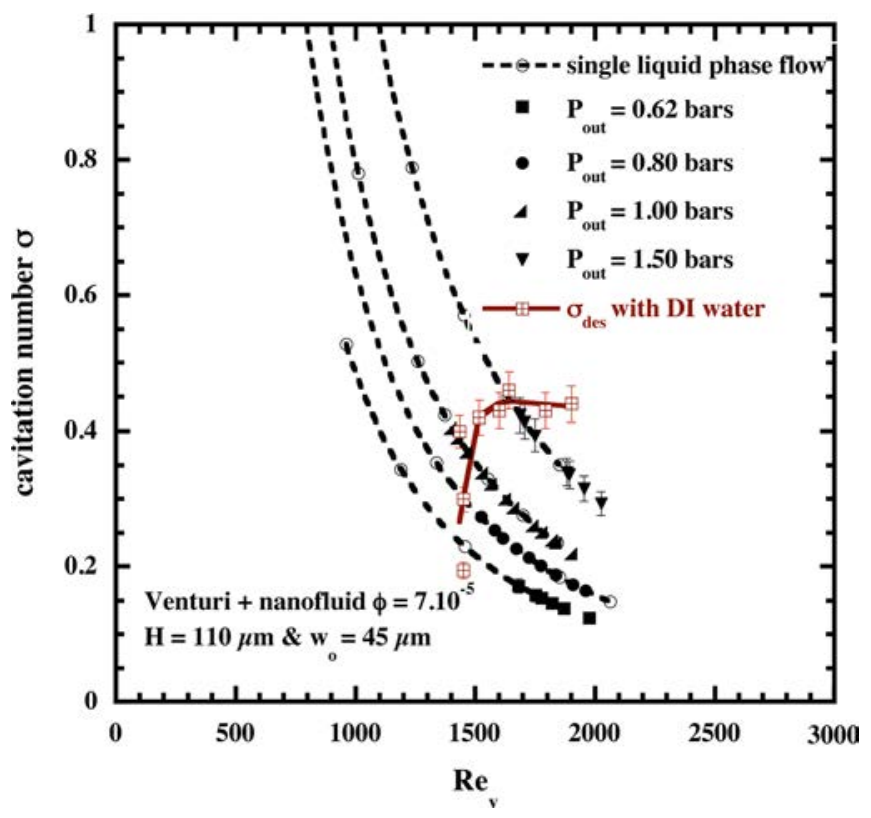

FIG. 14. (Color online) Arrays of $\sigma\left(\mathrm{Re}_{\mathrm{v}}\right)$ curves recorded at different fixed $\mathrm{P}_{\text {out }}$ values, for a micro venturi fed with a nanofluid with a solid volume concentration $\phi=7 \times 10^{-5}$. The desinent points recorded with pure DI water (Fig. 13) are reported here for a comparison with red crossed square symbols. It is obvious that the presence of the solid phase has no consequence neither on the onset of cavitation nor on the desinence. consistent with the fact that solid particles of radius above 1 $\mu \mathrm{m}$ have been filtered out. ${ }^{9}$ So, the lack of hysteresis observed formerly with diaphragms and nanofluids seems to be a consequence of unique interactions between nano aggregates and vortical structures associated with eddies in the shear layers downstream the diaphragms.

\section{CONCLUSION}

Hydrodynamic cavitation in microchannels has been observed and analyzed for high pressure loss flows of de ionized water emerging at variable outlet pressure. When increasing the volume flow rate through the micro-orifices, the transition from a single liquid phase to a cavitating twophase flow is delayed with respect to the critical value of the cavitation number associated with vapor pressure in the minimum section area. Since the roughness of the walls is low, and since there is a lack of solid nuclei in the stream, pure deionized water can withstand negative pressures corresponding to high velocity through the microdiaphragms and the microventuris. The onset of cavitation arises suddenly and the two phase flow is consistent with high shear rate cavitation and with sheet cavitation for the diaphragms and the venturis, respectively. Desinent cavitation is correlated to the output pressure and to the Reynolds number in the orifices. Vortical structures at extremely low pressures are strengthened by the high shear rate in the microchannel downstream the diaphragms. Then, the devices can withstand cavitating two-phase flows, even if the pressure of the jet has raised

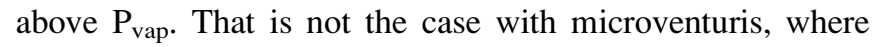
sheet cavitation occurs. In these devices, regular losses through the diffuser of the venturi are likely to change the desinent cavitation number. The presence of dilute nanoaggregates in the liquid did not give way to noticeable effects on the flow regimes through the venturis nor on the desinence of cavitation through the diaphragms. However, above a critical solid concentration, the liquid flowing through microdiaphragms cannot sustain negative pressures anymore, although nanosized particles should not change the tensile strength of water. That is the demonstration of interactions between nanoaggregates and vortical turbulent structures. Complementary experiments with a large range of solid volume concentration and sizes of particles have to be performed to confirm that conclusions with nanofluids. Hydrodynamic cavitation may be accurately predicted and performed inside microchannels with slots or venturi, with a low amount of liquid. That is, the demonstration that such "labs on chip" may find applications for a new approach of cavitation studies that conventionally require big substructures, and it opens the way to new trends when only a limited amount of liquid is available.

\section{ACKNOWLEDGMENTS}

This work was supported by the National Research Agency (contract Lunaprobe), the C.N.R.S. (grant Illumination and Lunaparc) and the Rhône - Alpes Land. One of us (M.M.) acknowledges the financial support of the Joseph Fourier University of Grenoble. The authors acknowledge helpful assistance of the technical support of the staff of the Nanofab 
facilities and of P. Brosse-Maron, from the Neel Institute of Grenoble. The authors acknowledge Pr O. Tillement's team from LPCML, Lyon (F) for providing nanoparticles.

${ }^{1}$ C. O. Iyer and S. L. Ceccio, "The influence of developed cavitation on the flow of a turbulent shear layer," Phys. Fluids 14, 3414 (2002).

${ }^{2}$ K. S. Suslick, M. M. Mdleleni, and J. T. Ries, "Chemistry induced by hydrodynamic cavitation,” J. Am. Chem. Soc. 119, 9303 (1997).

${ }^{3}$ V. S. Moholkar, P. S. Kumar, and A. B. Pandit, "Hydrodynamic cavitation for sonochemical effects," Ultrason. Sonochem. 6, 53 (1999).

${ }^{4}$ P. S. Kumar and A. B. Pandit, "Modeling hydrodynamic cavitation," Chem. Eng. Technol. 22, 1017 (1999).

${ }^{5}$ P. Braeutigam, M. Franke, Z.-L. Wu, and B. Ondruschka, "Role of different parameters in the optimization of hydrodynamic cavitation," Chem. Eng. Technol. 33, 932 (2010).

${ }^{6} \mathrm{X}$. Wang, J. Wang, P. Guo, W. Guo, and C. Wang, "Degradation of rhodamine $\mathrm{B}$ in aqueous solution by using swirling jet-induced cavitation combined with $\mathrm{H}_{2} \mathrm{O}_{2}$," J. Hazard. Mater. 169, 486 (2009).

${ }^{7}$ W. R. Moser, B. J. Marshik, J. Kingsley, M. Lemberger, R. Willette, A. Chan, J. E. Sunstrom IV, and A. Boye, "The synthesis and characterization of solid-state materials produced by high shear-hydrodynamic cavitation," J. Mater. Res. 10, 2322 (1995).

${ }^{8}$ S. H. Sonawane, S. P. Gumfekar, K. H. Kate, S. P. Meshram, K. J. Kunte, L. Ramjee, C. M. Mahajan, M. G. Parande, and M. Ashokkumar, "Hydrodynamic cavitation-assisted synthesis of nanocalcite," Int. J. Chem. Eng. 2010, 242963 (2010).

${ }^{9}$ H. B. Marshall, K. A. Mørch, A.P. Keller, and M. Kjeldsen, "Cavitation inception by almost spherical solid particles in water," Phys. Fluids 15, 545 (2003).

${ }^{10}$ K. A. Mørch, "Reflections on cavitation nuclei in water," Phys. Fluids 19, 072104 (2007).

${ }^{11}$ S. Vafaei, A. Purkayastha, A. Jain, G. Ramanath, and T. Borca-Tasciuc, "The effect of nanoparticles on the liquid-gas surface tension of $\mathrm{Bi}_{2} \mathrm{Te}_{3}$ nanofluids," Nanotechnology 20, 185702 (2009).

${ }^{12} \mathrm{~S}$. Vafaei and D. Wen, "Effect of gold nanoparticles on the dynamics of gas bubbles," Langmuir 26(10), 6902 (2010).

${ }^{13}$ L-S Fan, O. Hemminger, Z. Yu, and F. Wang, "Bubbles in nanofluids," Ind. Eng. Chem. Res. 46, 4341 (2007).

${ }^{14} \mathrm{~J}$. Li and P. Cheng, "Bubble cavitation in a microchannel," Int. J. Heat Mass Transfer 47, 2689 (2004).

${ }^{15}$ F. Caupin and E. Herbert, "Cavitation in water: A review," C. R. Phys. 7, 1000 (2006).
${ }^{16}$ E. Zwaan, S. Le Gac, K. Tsuji, and C.-D. Ohl, "Controlled cavitation in microfluidic systems,” Phys. Rev. Lett. 98, 254501 (2007).

${ }^{17}$ P. A. Quinto-Su, K. Y. Lim, and C.-D. Ohl, "Cavitation bubble dynamics in microfluidic gaps of variable height," Phys. Rev. E 80, 047301 (2009).

${ }^{18} \mathrm{C}$. Mishra and Y. Peles, "Cavitation in flow through a micro-orifice inside a silicon microchannel," Phys. Fluids 17, 013601 (2005).

${ }^{19} \mathrm{C}$. Mishra and Y. Peles, "Flow visualization of cavitating flows through a rectangular slot micro-orifice ingrained in a microchannel," Phys. Fluids 17, 113602 (2005).

${ }^{20} \mathrm{C}$. Mishra and Y. Peles, "An experimental investigation of hydrodynamic cavitation in micro-venturis," Phys. Fluids 18, 103603 (2006).

${ }^{21}$ R. Baviere, F. Ayela, S. Le Person, and M. Favre-Marinet, "Experimental characterization of water flow through smooth rectangular microchannels," Phys. Fluids 17, 098105 (2005).

${ }^{22}$ J. Judy, D. Maynes, and B. W. Webb, "Characterization of frictional pressure drop for liquid flows through microchannels," Int. J. Heat Mass Transfer 45, 3477 (2002).

${ }^{23}$ Tandiono, S.-W. Ohl, D. S.-W. Ow, E. Klaseboer, V. V. T. Wong, A. Camattari, and C.-D. Ohl "Creation of cavitation activity in a microfluidic device through acoustically driven capillary waves," Lab Chip 10, 1848 (2010).

${ }^{24}$ L. D'Agostino and A. J. Acosta, "A cavitation susceptibility meter with optical cavitation monitoring-Part One: Design concepts," J. Fluids Eng. 113, 261 (1991).

${ }^{25}$ I. E. Idelchik, Handbook of Hydraulic Resistance (Hemisphere, New York, 1986).

${ }^{26}$ J. Chevalier and F. Ayela, "Microfluidic on chip viscometer," Rev. Sci. Instrum. 79, 076102 (2008).

${ }^{27}$ C. Louis, R. Bazzi, C. A. Marquette, J.-L. Bridot, S. Roux, G. Ledoux, B. Mercier, L. Blum, P. Perriat, and O. Tillement, "Nanosized hybrid particles with double luminescence for biological labeling," Chem. Mater. 17, 1673 (2005).

${ }^{28}$ R. Prasher, D. Song, J. Wang, and P. Phelan "Measurements on nanofluid viscosity and its implications for thermal applications," Appl. Phys. Lett. 89, 133108 (2006).

${ }^{29}$ J. Chevalier, O. Tillement, and F. Ayela, "Rheological properties of nanofluids flowing through microchannels," Appl. Phys. Lett. 91, 233103 (2007).

${ }^{30}$ J. Chevalier, O. Tillement, and F. Ayela, "Structure and rheology of $\mathrm{SiO} 2$ nanoparticle suspensions under very high shear rates," Phys. Rev. E 80, 051403 (2009).

${ }^{31}$ R. E. A. Arndt, "Cavitation in vortical flows," Annu. Rev. Fluid Mech. 34, 143 (2002). 